NISTIR 7237

\title{
Chemical and Physical Characterization of Poly(p-phenylene-2,6-benzobisoxazole) Fibers Used in Body Armor
}

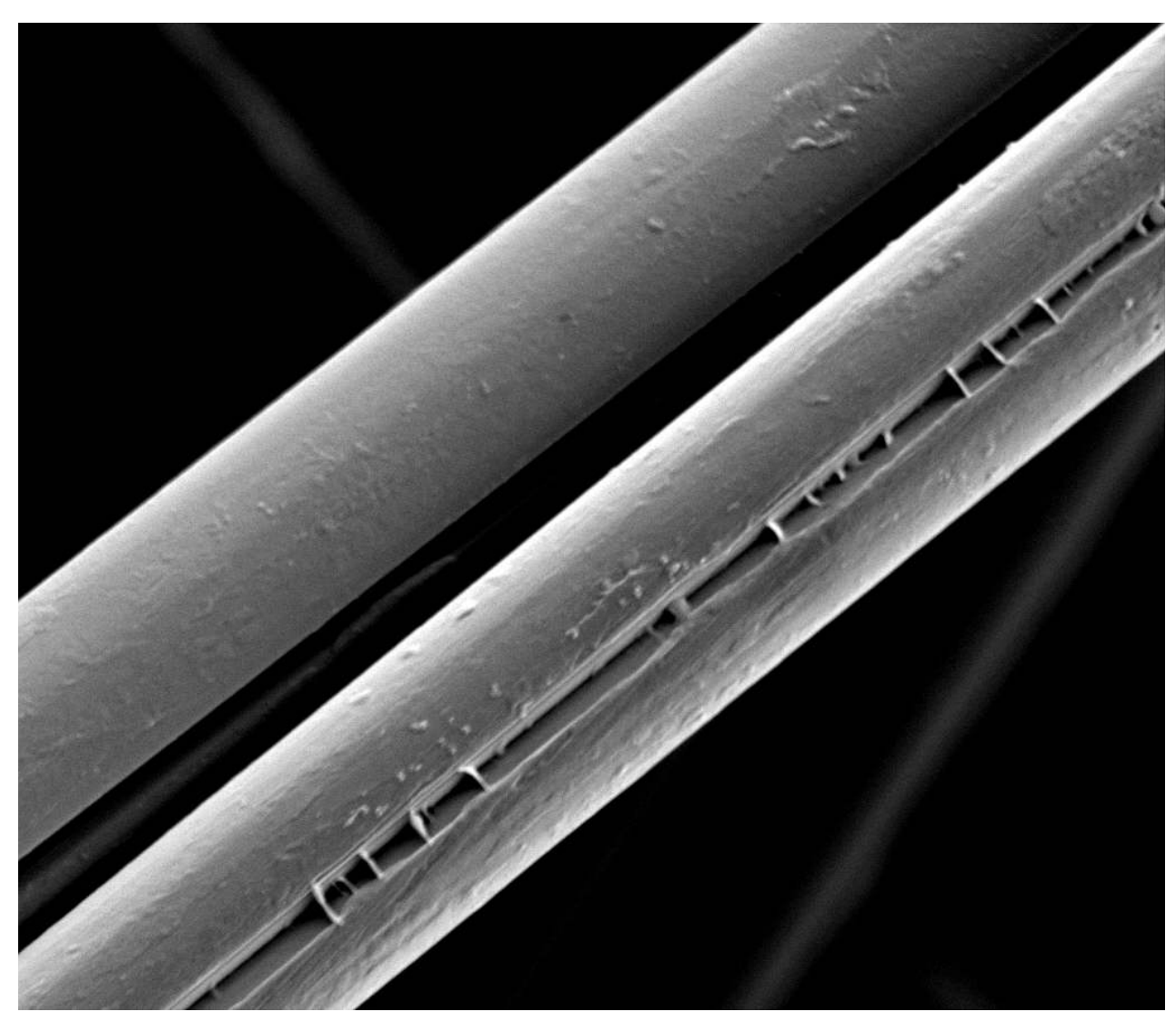


NISTIR 7237

\section{Chemical and Physical Characterization of Poly(p-phenylene-2,6-benzobisoxazole) Fibers Used in Body Armor}

Joannie Chin, Eric Byrd, Amanda Forster, Xiaohong Gu, Tinh Nguyen, Walter Rossiter,

Stephanie Scierka and Lipiin Sung Polymeric Materials Group Materials and Construction Research Division Building and Fire Research Laboratory

Paul Stutzman Inorganic Group Materials and Construction Research Division Building and Fire Research Laboratory

John Sieber

Spectrochemical Methods Group Analytical Chemistry Division Chemical Science and Technology Laboratory

Kirk Rice Office of Law Enforcement Standards Electronics and Electrical Engineering Laboratory

Sponsored by: National Institute of Justice Office of Justice Programs

May 2006

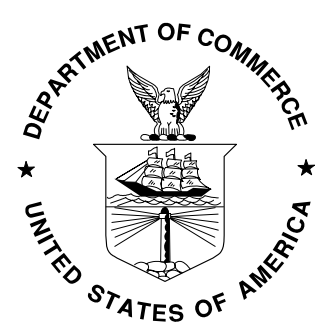

\section{U.S. DEPARTMENT OF COMMERCE}

Carlos M. Gutierrez, Secretary TECHNOLOGY ADMINISTRATION

Robert C. Cresanti, Under Secretary for Technology NATIONAL INSTITUTE OF STANDARDS AND TECHNOLOGY William A. Jeffrey, Director 


\begin{abstract}
Problems with the performance and durability of body armor based on poly(p-phenylene-2,6-benzobisoxazole) (PBO) fiber became apparent in the summer of 2003, when PBO-based body armor that had been manufactured less than 8 months earlier was penetrated by a bullet. Mechanical testing of the yarns taken from the penetrated vest indicated a $30 \%$ decrease in tensile strength relative to yarns taken from new, unworn PBO-based vests of the same model. A number of analytical metrologies were used to characterize the yarns, including chemical (elemental and molecular) analysis, mechanical testing, thermal analysis and microscopy. Attenuated total reflectance (ATR) infrared analyses of the yarns revealed differences in their degree of hydrolytic degradation as determined by the presence of benzamide structures. The rank order of reduction in benzamide, which corresponds to benzamide hydrolysis, correlates with the rank order reduction in tensile strengths for these same yarns.
\end{abstract}

Key Words: body armor, poly(p-phenylene-2,6-benzobisoxazole) (PBO), attenuated total reflectance (ATR), infrared (IR) spectroscopy, fiber, yarn, hydrolysis 


\section{INTRODUCTION AND OBJECTIVES}

In recent years, high performance fibers based on poly(p-phenylene-2,6benzobisoxazole) (PBO) have become prominent in high strength applications such as body armor, ropes and cables, and recreational equipment. Problems with the performance and durability of PBO-based body armor became apparent to the law enforcement community in the summer of 2003, when ballistic penetration of PBO-based body armor occurred in three separate incidents.

The first incident involved the shooting of a police officer near Pittsburgh, PA (hereinafter referred to as the “officer”) in June 2003. The bullet pierced the officer’s PBO-based body armor, which had been manufactured less than 8 months earlier. Mechanical testing of the yarns taken from the officer's vest indicated a $30 \%$ decrease in tensile strength relative to yarns taken from new, unworn PBO-based vests of the same model. Subsequently, two other incidents involving the penetration of PBO-based body armor by a bullet occurred that same year, but the evidentiary circumstances surrounding these incidents are more complicated and not as well documented and, as such, will not be discussed here.

These events prompted the Department of Justice (DOJ) and U.S. Attorney General John Ashcroft to announce a Body Armor Safety Initiative on November 18, 2003 [1], which tasked the National Institute of Justice (NIJ), the research, development and evaluation arm of DOJ, to address technical issues associated with PBO-based body armor. In response to the Attorney General's initiative, NIST’s Office of Law Enforcement Standards (OLES) and research groups within the NIST laboratories have undertaken a parallel, multi-phase effort to characterize chemical and physical degradation of PBO fiber and to correlate this degradation to body armor durability. 
The primary goals of the work described in this report, which comprises Phase I

of the research program, were to:

- Identify metrologies for characterizing the chemical, physico-mechanical and morphological properties of PBO fibers extracted from the officer's vest, new, unworn vests, and virgin $\mathrm{PBO}$ yarn.

- Utilize the above-identified analytical metrologies to carry out a comprehensive study of the chemical, physico-mechanical and morphological properties of the abovementioned yarns.

- Identify fiber properties that are correlated with the tensile properties of PBO.

The research detailed in this interim report is ongoing and will be updated as new findings become available. Future phases of this research program will address degradation mechanisms, accelerated aging and prediction of PBO fiber service life.

\section{OVERVIEW OF PBO}

Poly(p-phenylene-2,6-benzobisoxazole), or PBO, is a member of the benzazole polymer family and is characterized by the heterocyclic benzobisoxazole group in its main chain structure, as shown in Figure 1. The conjugated benzobisoxazole and phenyl rings in the PBO repeat unit contribute to extended $\pi$-electron delocalization and molecular rigidity, which provides high thermal stability and outstanding mechanical properties to this class of polymers. The chemistry and processing of PBO and related polymers has been documented [2, 3] and is not discussed here.

PBO fibers, as are the majority of the polybenzazole-based fibers, are extremely strong, tough and stiff, with tensile strengths and moduli superior to those of polyaramid or ultra-high molecular weight polyethylenes. Like carbon and other organic fibers, the axial compressive strength of PBO is quite low, being approximately $10 \%$ to $15 \%$ of the 
tensile strength. One explanation for this low compressive strength is that the intermolecular/interfibrillar forces in PBO are weak, allowing slippage of polymer chains or fibrils to occur under compressive load. Compressive failure is often accompanied by the formation of kink bands, which has been explained by some researchers to be the result of fibrillar instability [4].

The morphology and structure of PBO has been studied extensively using X-ray scattering, X-ray diffraction and various microscopic techniques, including scanning electron microscopy, transmission electron microscopy, and atomic force microscopy. It is generally accepted that PBO fiber has a fibrillar structure made up of extended, oriented PBO molecules, with individual fibril diameters ranging from $7 \mathrm{~nm}$ into the micron range [5]. Kitagawa et al. studied PBO using small angle X-ray scattering (SAXS) and transmission electron microscopy and observed that capillary voids nominally $2 \mathrm{~nm}$ to $3 \mathrm{~nm}$ in diameter and $30 \mathrm{~nm}$ long exist between the microfibrils in the fiber core. It was later determined that these capillary voids contain water that had been trapped in the fiber during the spinning process [6]. It has also been observed that the skin region of $\mathrm{PBO}$ fiber exhibits a higher degree of molecular orientation than the core region [7] and is essentially void-free [5].

A number of questions exist concerning the hydrolytic and ultraviolet (UV)visible light stability of PBO. The manufacturer has reported tensile strength degradation of PBO fiber following exposure to heat and moisture [8]. Only a few studies in the peerreviewed literature provide any data on the hydrolytic stability of PBO in aqueous and acidic conditions. As far back as 1995, researchers at NASA evaluated the chemical resistance of PBO and observed significant losses in tensile strength following immersion 
in water, hydrochloric acid, nitric acid, sulfuric acid, sodium chloride and sodium hypochlorite [9]. More recently, So et al. studied PBO fiber as well as model compounds of PBO in a variety of acidic and basic conditions [10]. Bond cleavage in PBO fiber was observed when it was dissolved in hot methane-sulfonic acid; no changes in relative molecular mass were observed following exposure to sulfuric acid, poly(phosphoric acid) or sodium hydroxide.

An extensive review conducted of the organic chemistry literature on hydrolysis of simple oxazoles and benzoxazole compounds can be found in Appendix A. This review summarizes findings that indicate, in general, that oxazoles and benzoxazoles undergo hydrolysis in conditions ranging from neutral to acidic, and at ambient as well as elevated temperatures.

A number of low relative molecular mass benzoxazole-containing compounds have been documented to undergo ring-opening upon exposure to ultraviolet and/or visible radiation $[11,12,13]$. Only one study could be found that documents the effects of ultraviolet-visible radiation on PBO fibers, in which substantial (> $90 \%$ ) loss in tensile strength was observed following $450 \mathrm{~h}$ exposure to $340 \mathrm{~nm}$ radiation [9]. 


\section{EXPERIMENTAL PROCEDURES*}

\section{$\underline{\text { Vest Materials }}$}

The comparative analysis of PBO materials included yarns from:

- The back panel of the officer's vest, manufactured in November 2002. This material will be referred to as the "officer's" vest. The front panel, where the bullet penetration occurred, is currently being retained as evidence and could not be obtained for analysis at the time of this writing.

- A new, unworn vest of the same model and construction as the officer's vest, style SMU-IIA+105130, manufactured in September 2003. This material will be referred to as the "new" vest.

- A vest from the National Law Enforcement and Corrections Technology Center (NLECTC) Compliance Test Program Archive, style SMU-IIA+105130, manufactured in March 2001; and submitted for compliance testing in May 2001. This material will be referred to as the "archive” vest.

- PBO spool yarn, manufactured in August 2003 and provided to NIST by the fiber manufacturer in May 2004 for this study. This material will be referred to as “virgin” yarn.

The ballistic panels from the vests described above consist of 20 layers of woven PBO fabric stacked together and diagonally stitched. For use in the field, the ballistic panel is typically inserted into a moisture-permeable plastic liner, referred to as the covering. The panel and covering are then inserted into a cotton fabric carrier.

\section{$\underline{\text { Yarn Extraction Procedure }}$}

Forty horizontally oriented (weft) yarns were extracted from the tenth layer of each vest. In the officer’s vest, the eleventh ayer was used because the tenth layer was

\footnotetext{
* Certain commercial equipment, instruments or materials are identified in this paper in order to specify the experimental procedure adequately. Such identification is not intended to imply recommendation or endorsement by the National Institute of Standards and Technology, nor is it intended to imply that the materials or equipment identified are necessarily the best available for this purpose.
} 
diagonally oriented. Nitrile gloves were worn throughout the extraction procedure to minimize contamination due to handling. Seams were first carefully removed from the ballistic panel to free the layers. Yarns were then extracted one by one from the bottom of the $10^{\text {th }}$ layer using with a small hook, and wrapped in aluminum foil that had been cleaned with methanol and acetone. This yarn removal process is depicted in Figure 2. Each foil packet was labeled with vest name, layer number and yarn number. Virgin yarn was used directly off of the spool.

\section{Tensile Testing}

To obtain yarn mechanical properties, tensile testing of yarns was carried out in accordance with ASTM D2256-02, “Standard Test Method for Tensile Properties of Yarn by the Single-Strand Method”, using an Instron Model 4482 test frame equipped with a $91 \mathrm{~kg}$ (200 lb) load cell, and pneumatic yarn and cord grips (Instron model 2714-006). Jaw separation was $7.9 \mathrm{~cm}$ (3.1 in) and cross-head speed was $2.3 \mathrm{~cm} / \mathrm{min}(0.9 \mathrm{in} / \mathrm{min})$. In this study, yarns were nominally $38.1 \mathrm{~cm}$ (15 in) long, and given 60 twists on a customdesigned yarn twisting device. This level of twist was maintained on the yarns as they were inserted into the pneumatic yarn and chord grips. Six replicates from each vest were tested to failure. The standard uncertainty of these measurements is typically $\pm 5 \%$.

\section{Microscopy}

Laser Scanning Confocal Microscopy—A Zeiss Model LSM510 reflection laser scanning confocal microscope (LSCM) was employed to characterize the surface morphology. The incident laser wavelength was $543 \mathrm{~nm}$. By moving the focal plane in 
the z-direction, a series of single images (optical slices) can be stacked and digitally summed over the z-direction to obtain a 3-D image. The z-direction step size was $0.5 \mu \mathrm{m}$ using objectives of 5x and 10x, and $0.1 \mu \mathrm{m}$ using objectives of 20x, 50x, and 150x.

Scanning Electron Microscopy—Scanning electron microscopy (SEM) analysis was carried out on a FEI Quanta 600 scanning electron microscope using secondary electron imaging at accelerating voltages ranging from $2 \mathrm{kV}$ to $15 \mathrm{kV}$. Fibers were mounted on aluminum stubs using carbon tape and were sputter coated with gold to conduct excess charge and enhance the secondary electron emission.

Atomic Force Microscopy—-To observe the surface morphology of the fibers on the nanoscale, atomic force microscopy (AFM) was carried out on a Dimension 3100 scanning probe microscope (Veeco Metrology) in tapping mode. Commercial silicon microcantilever probes (TESP, Veeco Metrology) were used. Topographic and phase images were obtained simultaneously using a resonance frequency of approximately $300 \mathrm{kHz}$ for the probe oscillation and a free-oscillation amplitude of $62 \mathrm{~nm} \pm 2 \mathrm{~nm}$.

\section{Thermogravimetric Analysis (TGA)}

TGA was carried out on a TA Instruments 2950 high resolution thermogravimetric analyzer. Yarn samples of approximately $30 \mathrm{mg}$ were coiled to fit into $500 \mu \mathrm{L}$ alumina sample pans. Samples were equilibrated at $27^{\circ} \mathrm{C}$ for $5 \mathrm{~min}$, and then ramped to $1000{ }^{\circ} \mathrm{C}$ at $10{ }^{\circ} \mathrm{C} / \mathrm{min}$. Analyses were carried out in both air and nitrogen atmospheres, with 5 replicates measured in air and 2 replicates of each sample measured in nitrogen. The primary parameters of interest were the temperature at which $5 \%$ mass loss was reached in the samples, as well as the $\%$ mass loss at $110{ }^{\circ} \mathrm{C}$. The relative 
standard uncertainty in the mass loss measurements is typically $\pm 0.1 \%$, and the standard uncertainty in the temperature scale is typically $\pm 0.1{ }^{\circ} \mathrm{C}$.

\section{$\underline{\text { X-ray Photoelectron Spectroscopy (XPS) }}$}

XPS measurements were performed on a Kratos Axis Ultra photoelectron spectrometer. Experiments were conducted at room temperature and an average base pressure of $1.3 \times 10^{-6} \mathrm{~Pa}$. The monochromatic $\mathrm{Al} \mathrm{K}_{\alpha} \mathrm{X}$-ray source was operated at $140 \mathrm{~W}(14 \mathrm{kV}, 10 \mathrm{~mA})$. The energy scale was calibrated with reference to the $\mathrm{Cu} 2 \mathrm{p}_{3 / 2}$ and $\mathrm{Ag} 3 \mathrm{~d}_{5 / 2}$ peaks at binding energies (BEs) of $932.7 \mathrm{eV}$ and $368.3 \mathrm{eV}$, respectively. A coaxial charge neutralization system provided charge compensation. Yarns were attached to the XPS sample holder using Cu tape. The analysis area for the highresolution spectra was $2 \mathrm{~mm} \times 1 \mathrm{~mm}$. The Na 1s, O 1s, N 1s, K 2p p/2, C 1s, P 2p, and Si 2p spectra were acquired at a take-off angle of $45^{\circ}$ and a pass energy (PE) of $20 \mathrm{eV}$, and a maximum acquisition time of 8 min per element.

Peak BEs were determined by referencing to the adventitious $C$ 1s photoelectron peak at $285.0 \mathrm{eV}$. Quantitative XPS analysis was performed with the Kratos VISION software (version 2.1.2). Atomic concentrations were calculated from the photoelectron peak areas by subtracting a linear-type background. The P 2p region was deconvoluted using mixed $70 \%$ Gaussian/30 \% Lorentzian components. Uncertainty in the peak BE measurement is typically $\pm 0.2 \mathrm{eV}$ and atomic concentration uncertainties are typically \pm 1 atomic $\%$. 


\section{$\underline{\text { X-ray Fluorescence (XRF) Spectroscopy }}$}

XRF analysis was carried out on a PANalytical model PW2404 wavelength dispersive XRF. Two 26 mm diameter fabric swatches from each vest were analyzed. Measurements were made in vacuum $(\approx 15 \mathrm{~Pa})$ using a Rh X-ray source operating at an average power of $3.0 \mathrm{~kW}$. Elements having higher energy characteristic X rays were measured using generator settings of $60 \mathrm{kV}$ and $50 \mathrm{~mA}$. Elements having lower energy characteristic $\mathrm{X}$ rays were measured using generator settings of $30 \mathrm{kV}$ and $100 \mathrm{~mA}$. Elemental composition calculations were carried out using the IQ+ fundamental parameters method, contained in the SuperQ operating system software of the XRF instrument. Calibration of the instrument and IQ+ method was carried out using reference materials, including NIST Standard Reference Materials (SRMs), which enabled the total relative standard uncertainty in elemental composition measurements to be estimated at $10 \%$.

\section{$\underline{\text { X-ray Diffraction (XRD) }}$}

X-ray powder diffraction patterns were obtained with a Bruker D8 Advance diffractometer using $\mathrm{Cu} \mathrm{K}_{\alpha}$ radiation $(\lambda=1.5405 \mathrm{~nm})$ with a step size of $0.02^{\circ}$ and a step time of 3 s. Specimens were analyzed as fabric swatches or as multiple yarn strands (nominally $3 \mathrm{~cm}$ long) tautly stretched and attached to a XRD sample holder with adhesive tape. Beam direction was parallel to the longitudinal axis of the fiber. Standard uncertainty in peak intensities is estimated to be $\pm 2 \%$. 


\section{Fourier Transform Infrared (FTIR) Spectroscopy}

Infrared analysis was carried out using a Nicolet Nexus FTIR equipped with a mercury-cadmium-telluride (MCT) detector and a SensIR Durascope attenuated total reflectance (ATR) accessory. Consistent pressure on the yarns was applied using the force monitor on the Durascope. Dry air was used as the purge gas. FTIR spectra were recorded between $4000 \mathrm{~cm}^{-1}$ and $700 \mathrm{~cm}^{-1}$ at three different locations on each yarn and were averaged over 128 scans. Spectral analysis, including spectral subtraction, was carried out using a custom software program developed in the Polymeric Materials Group at NIST to catalogue and analyze multiple spectra [14]. All spectra were baseline corrected and normalized using the aromatic C-H deformation peak at $848 \mathrm{~cm}^{-1}$. Standard uncertainties associated with this measurement are $\pm 2 \mathrm{~cm}^{-1}$ in wavenumber and $\pm 1 \%$ in absorbance.

\section{RESULTS AND DISCUSSION}

\section{Tensile Testing}

Tensile properties of yarns extracted from the back panel of the officer's vest, a new vest, and an archive vest are detailed in Table 1. The yarns from the officer's vest are clearly lower in ultimate tensile strength and ultimate tensile strain than the yarns from the new and archive vests, as well as the virgin yarn. The tensile strengths of the yarns from the archive vest are also lower than that of the new vest and virgin yarns. Interestingly, the moduli of the yarns from the three vests are not substantially different. 
The difference between the tensile properties of the virgin yarn and the vest yarns may be due to the degradation in strength that results from handling and weaving of the yarn into fabric.

\section{Microscopy}

In Figures 3-7, confocal microscopy and SEM images of fibers from vest and virgin yarns show morphological features that are tentatively identified as pits, transverse cracks and longitudinal grooves. Based on qualitative confocal microscopy analysis of 20 to 25 fibers from each vest, no prominent differences are observed in the surface morphology of the fibers from the three different vests.

Using optical and transmission and electron microscopy, similar transverse cracks observed by Chau et al. 1995 [15] have been postulated to be kink bands. Kink bands have also been observed in the microscopic analysis of other rigid rod polymers such as polyaramid and polybenzothiazole (PBT) [16,17]. As discussed earlier, kink bands result from compressive loading or bending encountered during processing, handling, or enduse. Kink bands are also known to initiate the formation of voids or cracks, which may subsequently degrade fiber tensile properties [18].

The longitudinal grooves are believed to have originated in the fiber spinning operation, but their exact cause is unknown. A 3-D image topographic profile generated by compiling confocal image slices of one such longitudinal groove is displayed in Figure 4. Groove depth and width were estimated by topographic measurements to be (0.70 to 0.84$) \mu \mathrm{m} \pm 0.05 \mu \mathrm{m}$, and (0.75 to 0.95$) \mu \mathrm{m} \pm 0.05 \mu \mathrm{m}$, respectively. 
Both AFM topographic and phase images of PBO fiber surfaces exhibit an oriented fibrillar morphology that has been observed by other researchers [19, 20, 21]. An AFM image of the officer's vest fibers are shown in Figure 8; similar results were obtained for the fibers from the other vests as well as from the virgin fiber. Patchy regions on the surface are attributed to sizing compounds that were applied after the fiber spinning operation. Similar features have also been observed by Tamargo-Martinez et al. [19]. In some instances, as shown in Figure 8, AFM analysis reveals disordering of the oriented fibrils, which may be associated with kink band formation. However, it is not certain that these disordered regions correspond to the cracks or kink bands observed via confocal microscopy and SEM, because it is difficult to find the exact location of a feature observed on two different size scales using two different imaging tools.

\section{Thermogravimetric Analysis (TGA)}

In thermogravimetry, the mass loss of a specimen is monitored as a function of time at a fixed temperature or as a function of temperature at a fixed heating rate. In polymers, thermal mass loss curves can provide information on the material's thermal stability, the composition of multicomponent materials, and/or the presence of low molecular mass or volatile components. Data from TGA analysis of PBO yarns are detailed in Table 2.

In a nitrogen atmosphere, the decomposition temperature at $5 \%$ mass loss of the yarns from the officer's vest is lower relative to the other two vest yarns and the virgin yarn; however, this small difference in light of the standard uncertainty is not statistically significant. Mass loss at $110{ }^{\circ} \mathrm{C}$, attributed to the loss of water and/or low relative 
molecular mass materials, is similar for the vest and virgin yarns. In air, little difference in the mass loss at $110{ }^{\circ} \mathrm{C}$ or the $5 \%$ decomposition temperature are observed. These thermogravimetry results are consistent with Kuroki et al. [22].

\section{$\underline{\text { X-ray Photoelectron Spectroscopy (XPS) }}$}

In XPS, specimens are irradiated with X rays, causing electrons to be ejected from the core atomic levels of atoms contained in the specimen. From the kinetic energies of the ejected electrons - termed photoelectrons - electron binding energies can be calculated which uniquely define a specific atom. Chemical shifts in binding energies can be correlated to changes in the chemical environment of an atom, and can be used to identify oxidation state and/or the nature of other atoms bound to that atom [23]. Because the mean-free paths of the ejected photoelectrons are extremely short, XPS is a surfacesensitive technique, providing information on the topmost $4 \mathrm{~nm}$ of a specimen surface. XPS atomic concentrations of elements found on the yarn surfaces are presented in Table 3. The surface elemental compositions of the yarns from the different vests are nominally identical. In addition to the expected carbon, oxygen and nitrogen, silicon, phosphorus, potassium, silicon and sodium are also observed. Phosphorus is postulated to originate from residual poly(phosphoric acid) spinning solvent and/or the fiber sizing that is applied by the fiber manufacturer. Silicon is also attributed to the fiber sizing. Sodium is believed to originate from the sodium hydroxide solution used to neutralize excess poly(phosphoric acid). Tamargo-Martinez et al. [19] also observed similar atomic concentrations in their XPS analysis of virgin PBO yarns. 
It is worth noting that the theoretical atomic concentrations of 77.8 atomic \% carbon, 11.1 atomic \% oxygen and 11.1 atomic \% nitrogen calculated from the PBO polymer repeat unit do not match the measured atomic concentrations of these elements listed in Table 3. Reasons for this discrepancy are the presence of sizing agents (as mentioned above), the presence of adventitious surface organic compounds, and/or the preferential surface enrichment of particular segments of the polymer chain.

The ratio of phosphorus and sodium is of interest because sodium hydroxide is used in the PBO manufacturing process to neutralize the poly(phosphoric acid) spinning solvent, which is contained in and on the fiber immediately after spinning. Complete neutralization of poly(phosphoric acid) by sodium hydroxide would result in the formation of a sodium phosphate compound, in which the atomic ratio of phosphorus to sodium should range between 0.3 to 1.0, depending on the specific type of sodium phosphate compound formed. The atomic ratio of phosphorus to sodium in the vest yarns ranges from 1.75 to 2.6, indicating that phosphorus is present in quantities beyond that which can be accounted for by sodium phosphate.

Photopeak energies were analyzed to determine the identity of the sodium and phosphorus compounds detected. The binding energy of the phosphorus 2p photopeak in the vest yarns falls in the range from $133.2 \mathrm{eV}$ to $133.4 \mathrm{eV}$ (referenced to carbon at 285.0 $\mathrm{eV}$ ) and that of the sodium 1s photopeak falls between $1071.5 \mathrm{eV}$ and $1071.7 \mathrm{eV}$. These photopeak energies are consistent with $\mathrm{Na}_{3} \mathrm{PO}_{4}$, which is documented to have phosphorus 2p binding energies between $132.5 \mathrm{eV}$ to $133.1 \mathrm{eV}$, and sodium 1s binding energies between $1071.2 \mathrm{eV}$ and $1071.5 \mathrm{eV}$ [24]. If poly(phosphoric acid) was present, the binding energy of the phosphorus 2p photoelectrons would be in the neighborhood of 
$135.4 \mathrm{eV}$, which is higher than the phosphorus detected in the vest yarns. Therefore, it is concluded that no detectable poly(phosphoric acid) residues are present on the fiber surface; rather, the phosphorus that is present is consistent with that of sodium phosphate or some other phosphate compound, possibly the fiber sizing.

\section{$\underline{\text { X-ray Fluorescence (XRF) Spectrometry }}$}

In XRF analysis, as in XPS, a specimen is irradiated with a beam of sufficiently short wavelength $\mathrm{X}$ rays, resulting in the generation of fluorescent $\mathrm{X}$ rays having energies characteristic of the elements present in the specimen. Quantitative information on the elements in the specimen can be obtained by measuring the count rates of the emitted $\mathrm{X}$ rays. XRF is a rapid, sensitive, and accurate method for detecting inorganic materials and metals in polymers, with minimal sample preparation needed (as compared to wet chemical elemental analysis methods) [25]. Unlike XPS, which is a surface analysis technique, XRF obtains elemental information from deeper in the fiber bulk.

Table 4 shows the elemental compositions of the vest yarns as measured by XRF. The two elements of particular interest, phosphorus and sodium, are found to be the most abundant and in essentially identical mass concentrations in each of the 3 vest materials. Phosphorus mass fractions range from $0.45 \%$ to $0.48 \%$. Using an inductively-coupled plasma (ICP) elemental analysis technique, a phosphorus content of $0.4 \%$ was found in virgin PBO yarn by Hu and Lesser [26], which is consistent with the present study.

As discussed previously in the section on XPS, neutralization of phosphoric acid by sodium hydroxide results in the formation of some type of sodium phosphate compound, in which the mass ratio of phosphorus to sodium could range from 0.45 to 
1.35, depending on the specific type of sodium phosphate compound formed. The phosphorus/sodium mass ratio in the vest yarns ranged from 1.45 to 1.59 , indicating that phosphorus is present in quantities beyond that which can be accounted for by sodium phosphate.

Figure 9 overlays phosphorus K-M series X-ray lines from each yarn specimen. The ratio of net count rates for these two peaks is 3.8. Data from other compounds of phosphorus and oxygen show that the net peak ratios are 3.1 for phosphorus pentoxide $\left(\mathrm{P}_{2} \mathrm{O}_{5}\right)$, 3.9 for lithium phosphate $\left(\mathrm{LiPO}_{3}\right)$, and 5.0 for phosphoric acid $\left(\mathrm{H}_{3} \mathrm{PO}_{4}\right)$. Thus, a peak ratio of 3.8 most closely corresponds to $\mathrm{PO}_{3}$, or phosphate, moiety. These results complement the XPS analyses, which also suggest that a phosphate-type compound accounts for the phosphorus that is detected.

It should be noted that the presence of a phosphate-containing sizing compound on the fiber surface could potentially absorb the fluorescent $\mathrm{X}$ rays generated by atoms inside the fibers and would complicate the analysis of the phosphorus $\mathrm{K}-\mathrm{M}$ series $\mathrm{X}$-ray lines. Thus, the presence of the sizing makes it difficult to determine the exact nature of any phosphorus-containing species inside the fiber. To make a definitive identification of phosphorus compounds, including phosphoric acid, ${ }^{13} \mathrm{P}$ nuclear magnetic resonance (NMR) may be a more useful technique.

\section{$\underline{\text { X-ray Diffraction }}$}

The scattering of X rays by atoms in a crystal lattice results in a diffraction pattern that is characteristic of the crystal structure. In highly crystalline polymers such as PBO, 
an X-ray diffraction pattern can reveal the degree of crystallinity, crystal orientation, and provide input for the calculation of crystal lattice parameters [27].

According to detailed crystal structure analysis performed by Tashiro et al., the proposed structure for PBO is a monoclinic cell with a $=11.2 \AA, \mathrm{b}=3.57 \AA, \mathrm{C}=12.01 \AA$, and $\gamma=100.6^{\circ}$, corresponding to 2 polymer repeat units per cell [28]. The PBO chain in the crystal structure has been observed to have an almost perfectly planar conformation. Davies et al. have reported differences in crystallite orientation between the skin and the core regions of PBO fiber analyzed with X-ray diffraction [29].

The equatorial X-ray diffractograms shown in Figure 10 reflect the intermolecular arrangement between packed polymer chains in the PBO fibers. Diffractograms obtained in our lab are consistent with those reported by other researchers [29, 30, 31, 32]. Major crystalline peaks are observed at $2 \theta=16.2^{\circ}, 27.5^{\circ}$, and $32.7^{\circ}$, corresponding to crystal lattice d-spacings of $0.547 \mathrm{~nm}, 0.324 \mathrm{~nm}$ and $0.274 \mathrm{~nm}$, respectively.

No significant differences in the locations of the crystalline peaks or any changes in the peak structures are observed for yarns or fabric swatches from the three vests. Differences in peak intensity are most likely due to differences in the packing density of the fiber samples. Substantial changes in the crystal lattice structure would be accompanied by changes in peak shape and location, as seen by Tamargo-Martinez et al., who reported significant changes in the equatorial X-ray diffractogram of PBO fiber as it is heated up to $800{ }^{\circ} \mathrm{C}[30]$. 


\section{Infrared Spectroscopy}

The interaction between materials and the infrared region of the electromagnetic spectrum provides valuable information on the molecular structure of organic materials, including organic polymers. Specific functional groups absorb at given frequencies corresponding to their vibrational modes. Changes in the intensities or frequencies of observed spectral peaks can be correlated to changes in the molecular structure of the compound. This type of information is valuable for mechanistic and kinetic studies of polymer degradation.

Figures 11(a) and 11(b) show the ATR infrared spectra of the vest yarns compared with the spectrum of virgin yarn. The primary infrared bands are listed in Table 5. Assignments are made on the basis of literature data [30,33, 34, 35, 36] and studies carried out in our lab using model compounds. Benzoxazole and 2-phenyl benzoxazole model compounds were analyzed to identify the peaks in the PBO spectrum that are attributed to the oxazole or benzoxazole component in the PBO structure. Two small peaks, shown on an expanded scale in Figure 11(c), are observed at $1726 \mathrm{~cm}^{-1}$ and $1691 \mathrm{~cm}^{-1}$ in all yarns analyzed. These peaks have not been reported in any previous publications or observed in our analysis of benzoxazole-containing model compounds.

Visual examination of the yarn spectra does not highlight any obvious chemical differences between the yarns. In many instances, chemical changes due to polymer degradation are often difficult to detect directly. Spectral subtraction, in which a reference spectrum is subtracted from the spectrum of a material of interest, is often helpful in extracting small chemical changes and providing information on the formation and depletion of specific functional groups. 
Figure 12 shows the difference spectra that result when the infrared spectrum of the virgin yarn is subtracted from each of the vest yarn spectra. Qualitatively similar difference spectra are obtained when the spectrum of the yarns from the new vest were subtracted from the officer and archive vest yarn spectra. Downward-pointing, or negative, peaks in the difference spectra are species that are lower in concentration relative to the reference spectrum (virgin yarn, in this case) and upward-pointing, or positive, peaks are species that are higher in concentration relative to the reference material or new species that are not originally present in the reference material.

The primary negative peaks in the difference spectra of the vest yarns are seen at $931 \mathrm{~cm}^{-1}, 1072 \mathrm{~cm}^{-1}, 1422 \mathrm{~cm}^{-1}, 1440 \mathrm{~cm}^{-1}, 1506 \mathrm{~cm}^{-1}, 1560 \mathrm{~cm}^{-1}, 1588 \mathrm{~cm}^{-1}, 1657 \mathrm{~cm}^{-1}$ and $3400 \mathrm{~cm}^{-1}$. These peaks are not found in the unsubtracted infrared spectra of the vest yarns or the virgin yarn. However, subsequent infrared analysis of a known benzoxazole hydrolysis product, $\mathrm{N}-\left(2\right.$-phenylhydroxybenzamide), revealed peaks at $931 \mathrm{~cm}^{-1}$, $1070 \mathrm{~cm}^{-1}, 1441 \mathrm{~cm}^{-1}, 1657 \mathrm{~cm}^{-1}$ and $3400 \mathrm{~cm}^{-1}$ that matched a number of the negative peaks in the difference spectrum.

The following degradation scenario is proposed on the basis of the ATR-infrared data available at this time: it is postulated that benzamide-type structures similar to $\mathrm{N}$-(2phenylhydroxybenzamide) exist in the vest yarns as well as the virgin yarn. These species are found in low concentrations and are not visible in the original unsubtracted infrared spectra. These species are possibly the result of benzoxazole ring hydrolysis that occurred during processing/storage/handling, UV-visible light exposure (as documented for benzoxazole-containing model compounds in [37] and [38]), or some combination of these. As the yarns are woven, fabricated into body armor, and worn in 
the field, additional hydrolysis of the benzamide structures could occur. Benzamide hydrolysis would result in the formation of aminophenol and benzoic acid species, and a consequent reduction in the concentration of the original benzamide structures. This decrease in benzamide concentration is the origin of the negative peaks that appear when the virgin yarn infrared spectrum is subtracted from the infrared spectra of the vest yarns.

The difference spectrum of the officer's vest yarn contains negative benzamide peaks with the highest intensity (absorbance), followed by the archive vest and the new vest, in decreasing order of intensity. This indicates that the degree of benzamide hydrolysis is greatest in the officer's vest, followed by the archive vest, and the least in the new vest, relative to the virgin yarn. This rank order in benzamide peak absorbance follows the same rank order of tensile strength loss reported earlier. Figure 13 shows a plot of vest yarn tensile strength plotted against the absorbance of negative peaks corresponding to benzamide species. A negative correlation is observed to exist between tensile strength and benzamide peak spectral absorbance.

A number of positive peaks in the difference spectra correspond to peaks that are present in the original spectrum of virgin PBO. This could indicate that a higher concentration of benzoxazole structures is present in the vest yarns relative to the virgin yarn. The remaining positive peaks in the difference spectra are not identified at the present time; infrared analysis of known benzoxazole degradation products, such as benzoic acid and aminophenol will be carried out to assign these peaks.

Support for the hydrolysis of benzoxazole to benzamide and the regeneration of benzoxazole from benzamide is given by Jackson et al. [39]. When 2-phenylbenzoxazole (1) is heated in an acidic medium, $\mathrm{N}$-(2-phenylhydroxybenzamide) (2) is first formed: 


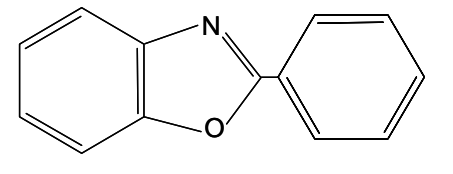

(1)

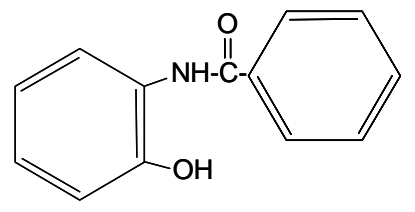

(2)

$\mathrm{N}$-(2-phenylhydroxybenzamide) can then further hydrolyze to 2-aminophenol and benzoic acid ((3) and (4), respectively), or re-convert to 2-phenylbenzoxazole (1).

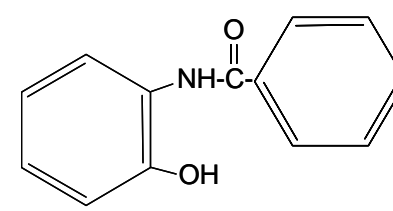

(2)

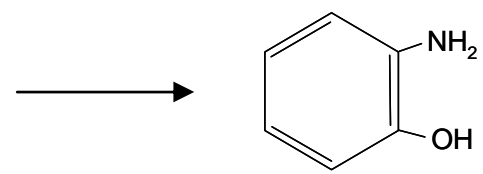

(3)<smiles>O=C(O)c1ccccc1</smiles>

(4)

Both benzoxazole hydrolysis and benzamide hydrolysis mechanisms potentially cause tensile strength degradation in $\mathrm{PBO}$ - the first by disrupting the conjugated rigid rod structure and creating a polyaramid-type structure in its place; the second by chain scission. In the present study, the latter mechanism appears to be predominant. In theoretical models of fiber tensile strength and modulus developed by Termonia et al.[40] and Jones and Martin [41], both groups state that decreases in polymer chain length are more detrimental to tensile strength than to elastic modulus. These observations are consistent with the vest yarn tensile properties reported in this study, in which degradation was observed in tensile strength but not elastic modulus. 


\section{SUMMARY}

A number of analytical metrologies were used in characterizing the chemical, physico-mechanical and morphological properties of PBO yarns from an officer's vest penetrated by a bullet, a new vest, a vest from the NLECTC Compliance Test Program archive, and virgin PBO yarn. Metrologies used to characterize the yarns included chemical (elemental and molecular) analysis, mechanical testing, thermal analysis and microscopy. Results of these analyses were used to determine if any chemical or morphological differences exist between the four different yarns and if any of these properties were correlated to yarn tensile properties.

Very few differences were observed in the surface or bulk elemental composition of the yarns; phosphate compounds that were detected on all yarns were attributed to either fiber sizing materials or acid neutralization products. Additionally, no detectable differences were observed in the crystal structure of the fibers nor in their surface morphologies. Transverse and longitudinal cracks were observed, however, on all of the analyzed fibers.

ATR infrared analyses of the yarns revealed differences in their degree of hydrolytic degradation as determined by the presence of benzamide structures. Benzamide structures were observed to different degrees in the officer's vest yarn, new vest yarn, archive vest yarn and virgin PBO yarn. The rank order of reduction (hydrolysis) in benzamide species correlates with the rank order reduction in tensile strengths for these same yarns. This ordering is significant since benzamide hydrolysis is believed to contribute to tensile strength loss via chain scission. 


\section{ACKNOWLEDGMENTS}

The authors thank NIST’s Office of Law Enforcement Standards (OLES) and the National Institute of Justice (NIJ) for their support of this research, as well as the Tekne Group for assistance in tensile testing. 
Table 1: Tensile Properties of Vest Yarns

\begin{tabular}{|c|c|c|c|c|}
\hline & $\begin{array}{c}\text { Tensile Strength } \\
(\mathrm{GPa})\end{array}$ & $\begin{array}{c}\text { at Break } \\
(\%)\end{array}$ & $\begin{array}{l}\text { at Break } \\
(\mathrm{GPa})\end{array}$ & $\begin{array}{l}\text { Break Point } \\
\quad(\mathrm{N} \mathrm{m})\end{array}$ \\
\hline \multicolumn{5}{|l|}{ Officer } \\
\hline$\overline{\text { Mean }^{\star}}$ & 3.22 & 2.50 & 136.61 & 0.31 \\
\hline Std Dev & 0.24 & 0.17 & 2.61 & 0.04 \\
\hline Minimum & 2.90 & 2.32 & 134.00 & 0.26 \\
\hline Maximum & 3.48 & 2.68 & 140.48 & 0.35 \\
\hline \multicolumn{5}{|l|}{ New } \\
\hline Mean & 4.78 & 3.29 & 141.80 & 0.61 \\
\hline Std Dev & 0.19 & 0.12 & 3.61 & 0.05 \\
\hline Minimum & 4.47 & 3.18 & 137.98 & 0.53 \\
\hline Maximum & 5.02 & 3.42 & 146.24 & 0.66 \\
\hline \multicolumn{5}{|l|}{ Archive } \\
\hline Mean* & 3.65 & 2.65 & 141.60 & 0.37 \\
\hline Std Dev & 0.10 & 0.06 & 5.00 & 0.02 \\
\hline Minimum & 3.53 & 2.55 & 134.89 & 0.35 \\
\hline Maximum & 3.78 & 2.74 & 148.32 & 0.39 \\
\hline \multicolumn{5}{|l|}{ Virgin } \\
\hline$\overline{\text { Mean* }^{\star}}$ & 5.34 & 3.52 & 147.11 & 0.91 \\
\hline Std Dev & 0.16 & 0.12 & 2.70 & 0.05 \\
\hline Minimum & 4.85 & 3.19 & 142.85 & 0.75 \\
\hline Maximum & 5.53 & 3.67 & 152.84 & 0.99 \\
\hline
\end{tabular}


Table 2: Thermogravimetric Analysis of Vest Yarns

\section{Sample ID \\ Nitrogen Atmosphere}

Percent Mass Loss at $110{ }^{\circ} \mathrm{C}$

$\begin{array}{ccc}\text { Officer } & 0.10 \pm 0.04 & 692.1 \pm 1.5 \\ \text { New } & 0.13 \pm 0.06 & 694.4 \pm 1.5 \\ \text { Archive } & 0.17 \pm 0.10 & 694.0 \pm 2.8 \\ \text { Virgin } & 0.26 \pm 0.09 & 699.4 \pm 8.2\end{array}$

\section{Air Atmosphere}

Officer

New

Archive

Virgin
$0.33 \pm 0.10$

$0.32 \pm 0.09$

$0.28 \pm 0.08$

$0.48 \pm 0.17$
$5 \%$ Decomposition Temperature $\left({ }^{\circ} \mathrm{C}\right)$

$699.4 \pm 8.2$

$632.0 \pm 3.4$

$632.9 \pm 4.8$

$633.6 \pm 2.5$ 


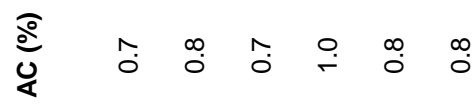

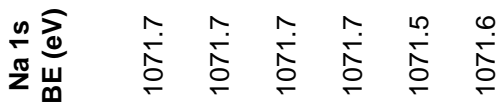

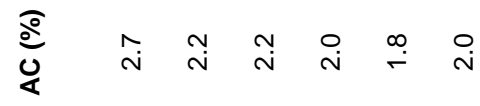

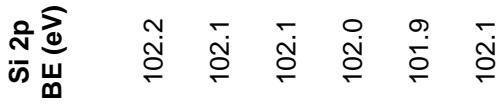

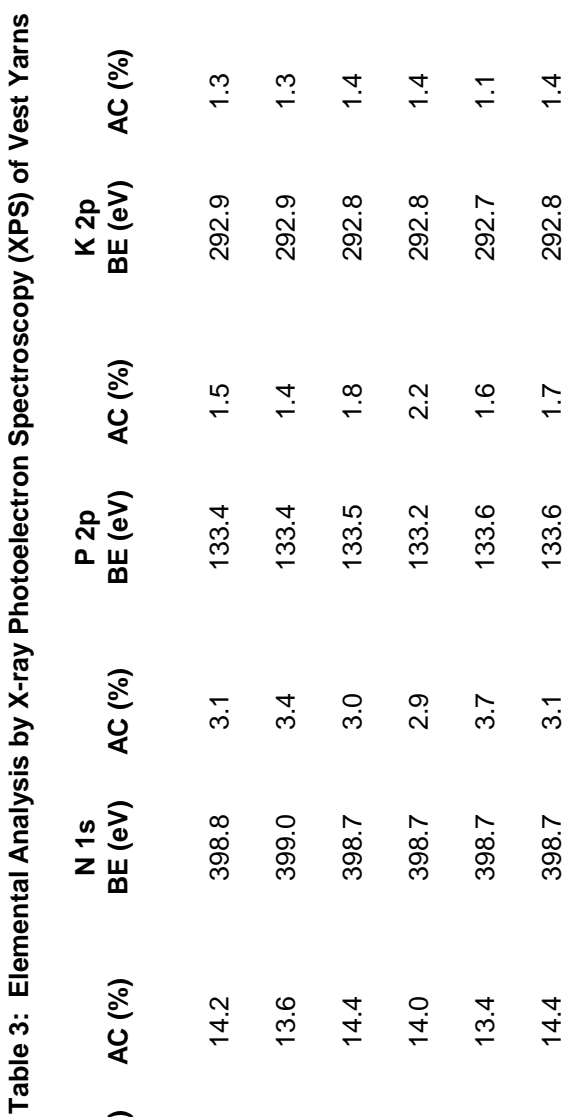

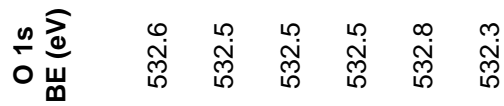

$$
\begin{aligned}
& \text { ஓ }
\end{aligned}
$$

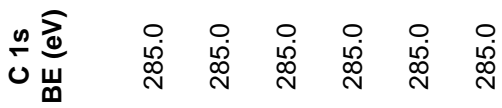

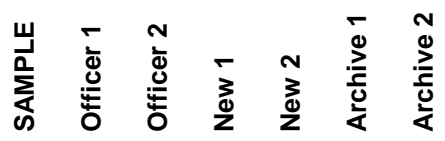


Table 4: Elemental Analysis by X-ray Fluorescence Spectroscopy of Vest Yarns (All values in mass fraction \%)

\section{$\begin{array}{llllll}\text { Officer } 1 & \text { Officer } 2 & \text { New } 1 & \text { New } 2 & \text { Archive } 1 & \text { Archive } 2\end{array}$}

$\begin{array}{lcccccc}\text { Mass (g) } & 0.17 & 0.20 & 0.21 & 0.20 & 0.22 & 0.26 \\ \text { Area } & 16.0 & 17.2 & 18.2 & 19.8 & 16.0 & 25.2 \\ \left.\mathbf{( c m}^{2}\right) & & & & & & \\ \mathrm{Na} & 0.29 & 0.30 & 0.33 & 0.32 & 0.29 & 0.29 \\ \mathrm{Al} & * & * & 0.002 & * & 0.003 & 0.006 \\ \mathrm{Si} & 0.030 & 0.027 & 0.024 & 0.029 & 0.021 & 0.023 \\ \mathrm{P} & 0.45 & 0.46 & 0.48 & 0.47 & 0.46 & 0.47 \\ \mathrm{~S} & * & * & * & * & 0.003 & 0.002 \\ \mathrm{Cl} & 0.010 & 0.010 & 0.009 & 0.011 & 0.010 & 0.008 \\ \mathrm{~K} & 0.051 & 0.050 & 0.053 & 0.048 & 0.045 & 0.045 \\ \mathrm{Ca} & 0.018 & 0.019 & 0.022 & 0.028 & 0.014 & 0.013 \\ \mathrm{Ti} & 0.005 & * & 0.004 & 0.004 & 0.002 & 0.003 \\ \mathrm{Fe} & 0.009 & 0.008 & 0.007 & 0.008 & 0.002 & 0.003 \\ \mathrm{Cu} & 0.003 & 0.003 & 0.003 & 0.003 & * & 0.001 \\ \mathrm{Sr} & 0.023 & 0.008 & 0.023 & 0.022 & 0.003 & 0.006\end{array}$

\footnotetext{
* Not detected above $0.001 \%$
} 
Table 5: FTIR-ATR Band Assignments for PBO Fiber

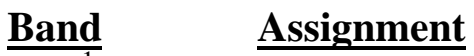 \\ $\left(\mathrm{cm}^{-1}\right)$ \\ 3097 \\ Aromatic C-H stretch from benzene between oxazole rings, closer to oxygen \\ 3069 \\ Aromatic C-H stretch from benzene between oxazole rings \\ 3040 \\ Aromatic C-H stretch from phenyl ring \\ 2956 \\ Aliphatic C-H stretch (sizing) \\ 2910 \\ Aliphatic C-H stretch (sizing) \\ 2851 \\ Aliphatic C-H stretch (sizing) \\ 1726 \\ 1691 \\ 1619 \\ 1577 \\ 1557 \\ 1496 \\ 1461 \\ 1412 \\ 1367 \\ 1329 \\ 1308 \\ 1276 \\ 1210 \\ 1147 \\ 1114 \\ 1056 \\ 1010 \\ 925 \\ 914 \\ 869 \\ 848 \\ 821 \\ $\mathrm{C}=\mathrm{C}$ stretching in substituted aromatic rings, cyclic $\mathrm{C}=\mathrm{N}$ stretching \\ Skeletal vibrations in conjugated system/benzoxazole ring \\ Skeletal vibrations in conjugated system/benzoxazole ring \\ Skeletal vibrations in conjugated system/benzoxazole ring \\ Skeletal vibrations in conjugated system/benzoxazole ring \\ 701 \\ C-N stretching \\ C-N stretching \\ $\mathrm{C}-\mathrm{C}$ stretching in carbons linking oxazole and aromatic ring; O-C=N \\ stretching \\ Asymmetric stretching of unsaturated cyclic ether \\ Aromatic C-H in-plane bending \\ Asymmetric stretching of unsaturated cyclic ether \\ Aromatic C-H in-plane bending \\ Symmetric C-O-C stretching of cyclic ether \\ Symmetric C-O-C stretching of cyclic ether \\ Aromatic C-H out of plane bending \\ Aromatic C-H out of plane bending \\ Aromatic C-H out of plane bending \\ Aromatic C-H out of plane bending
}




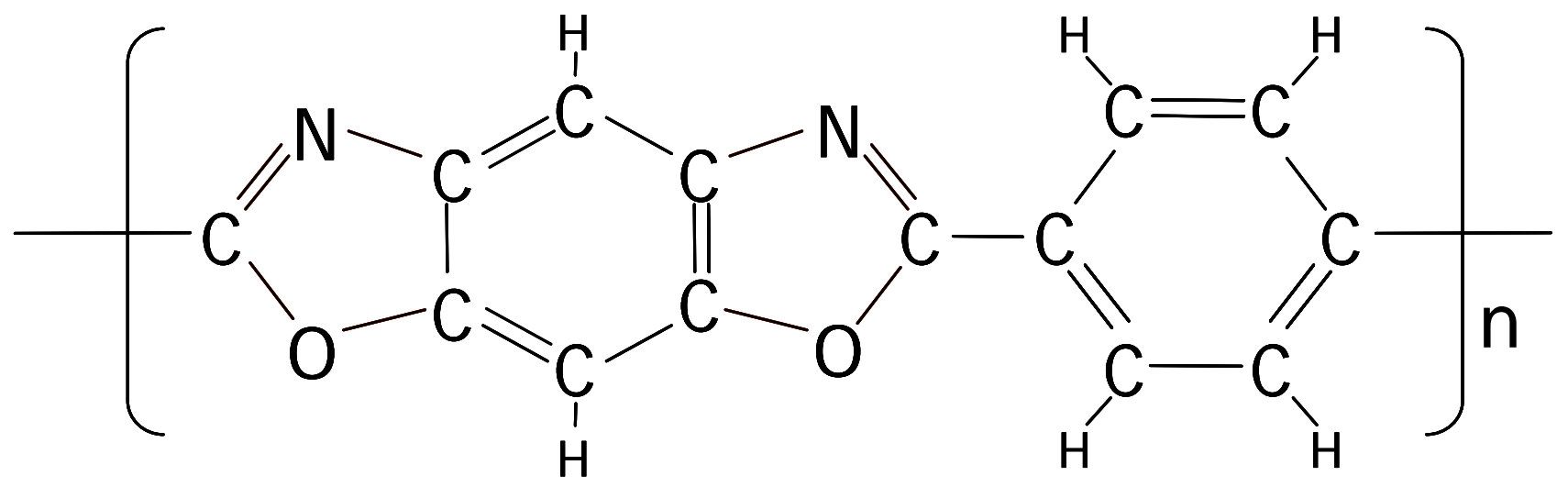

Figure 1: Chemical structure of poly(p-phenylene-2,6-benzobisoxazole), or PBO 

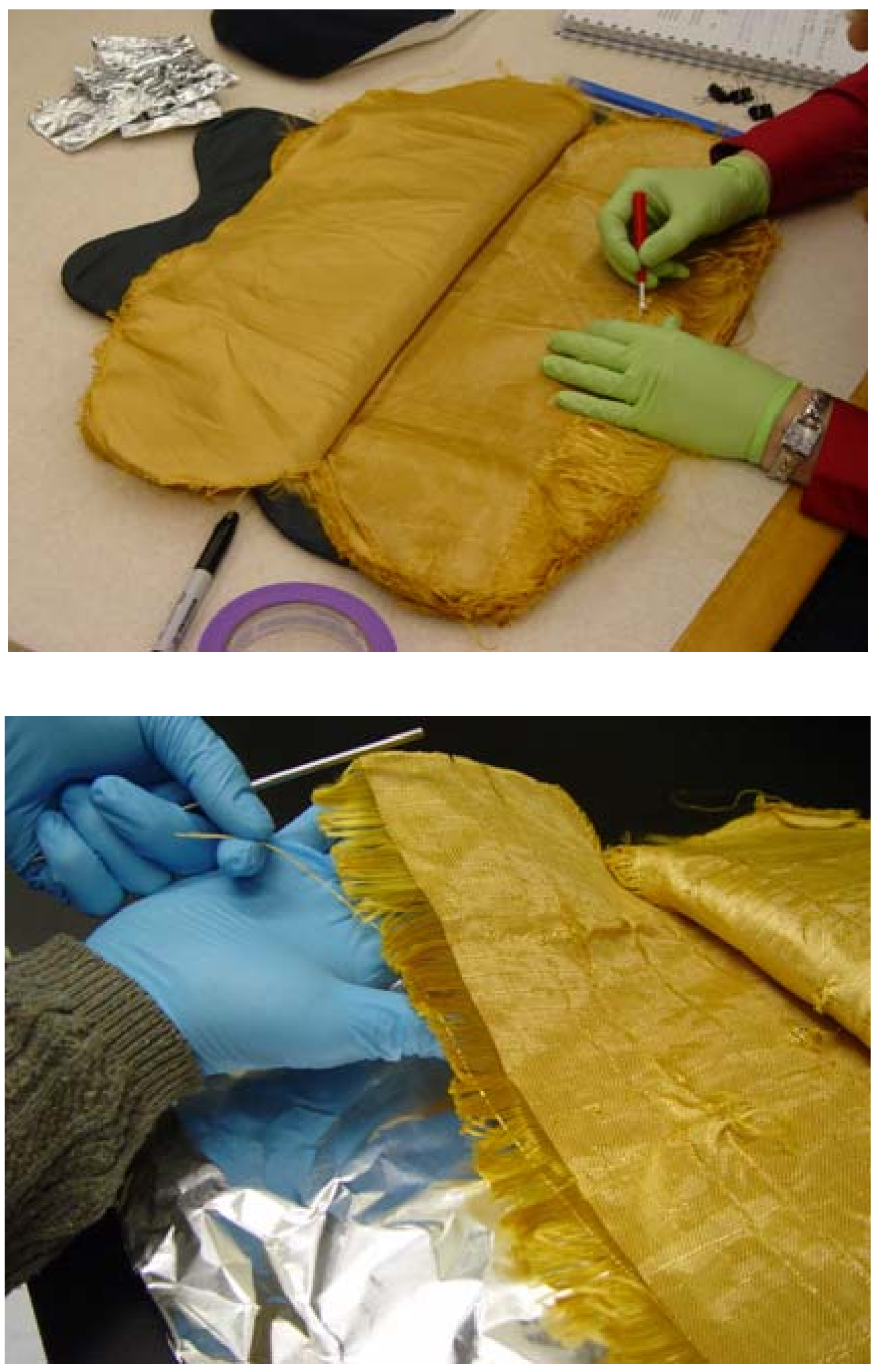

Figure 2: Extraction of yarns from ballistic panels in vests. 


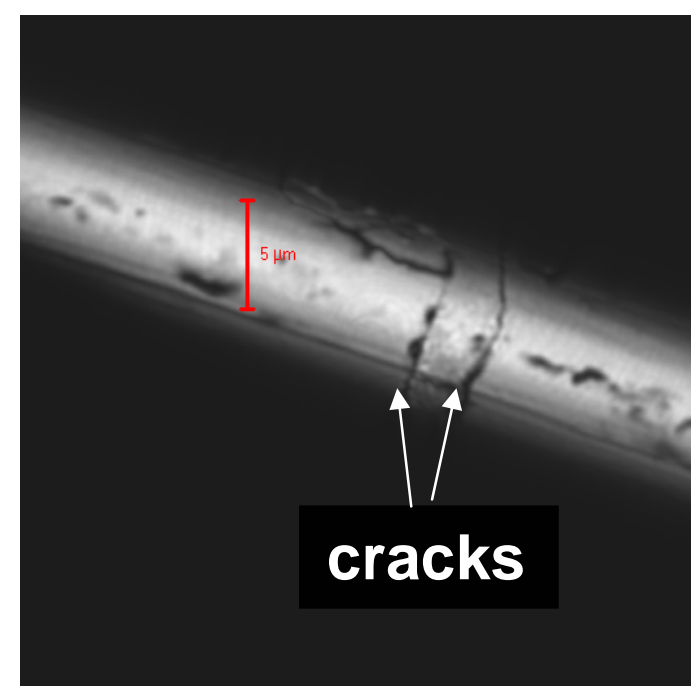

(a)

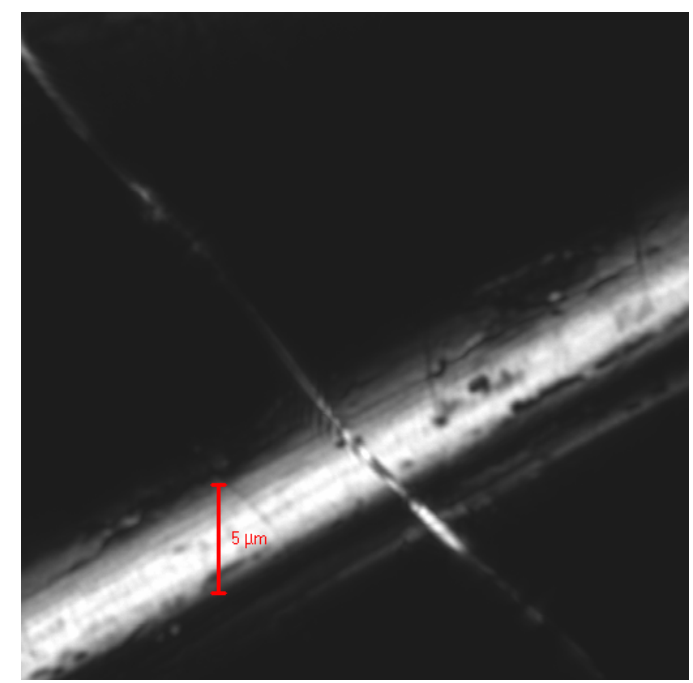

(c)

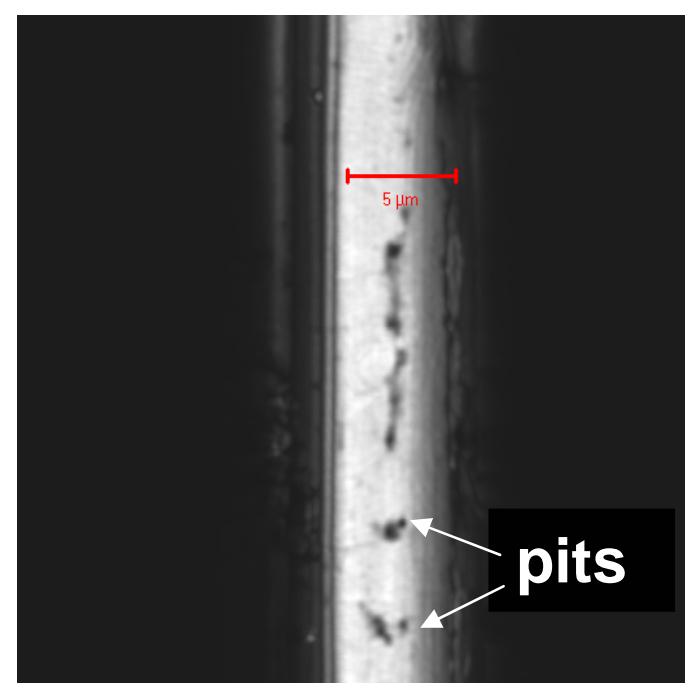

(b)

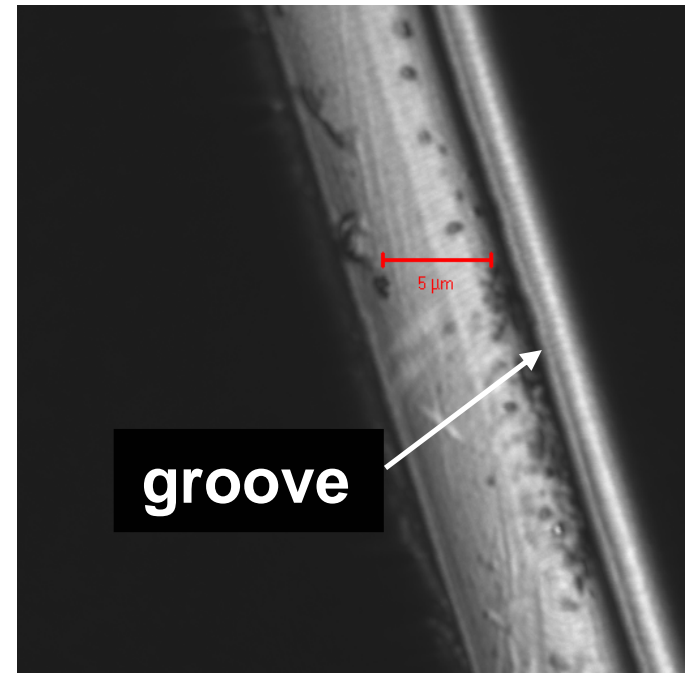

(d)

Figure 3: Confocal microscope images of fibers from (a) officer's vest, (b) new vest, (c) archive vest, and (d) virgin PBO fiber. 

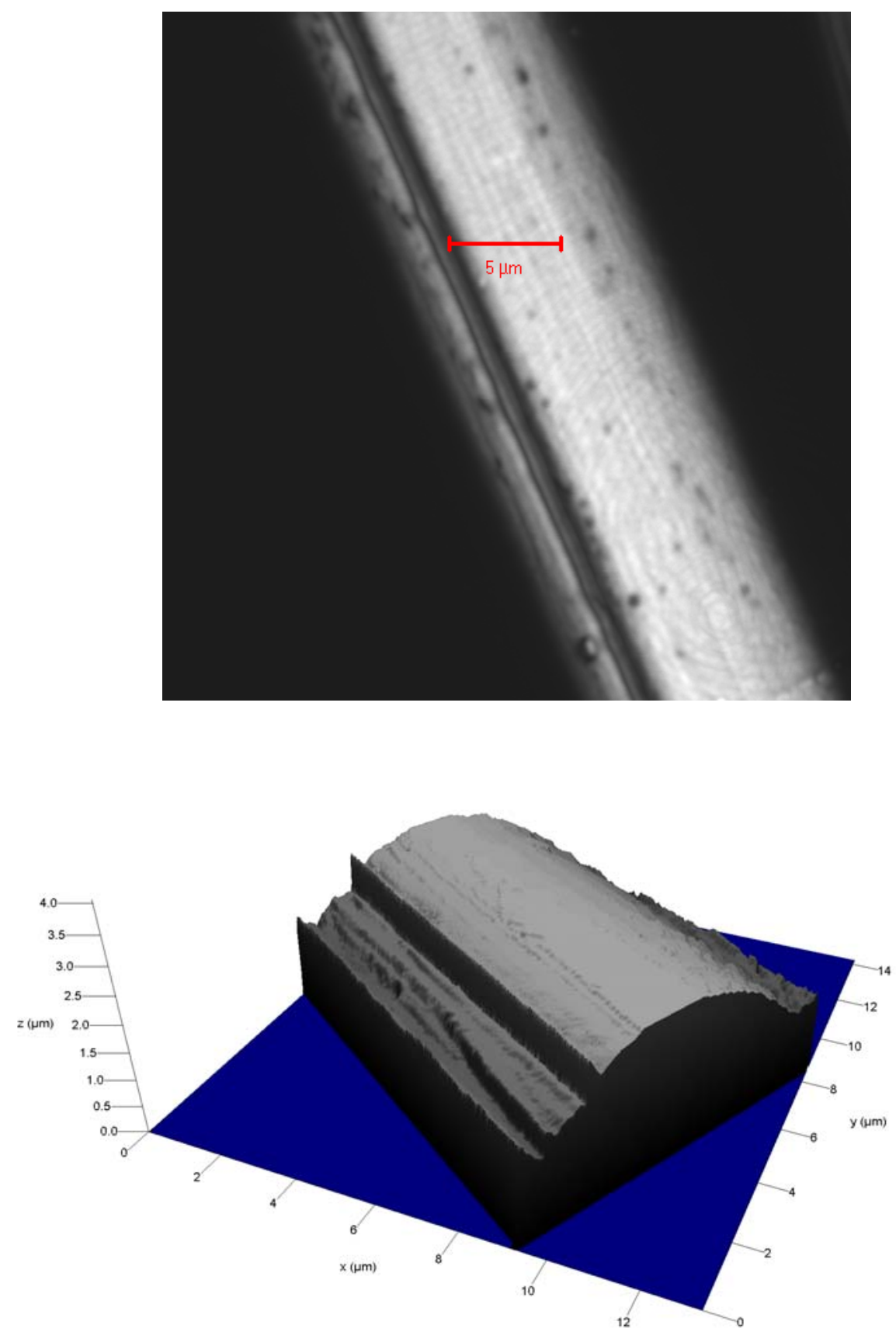

Figure 4: 3-D profile of the longitudinal groove seen in the confocal microscope image of virgin fiber, above. 


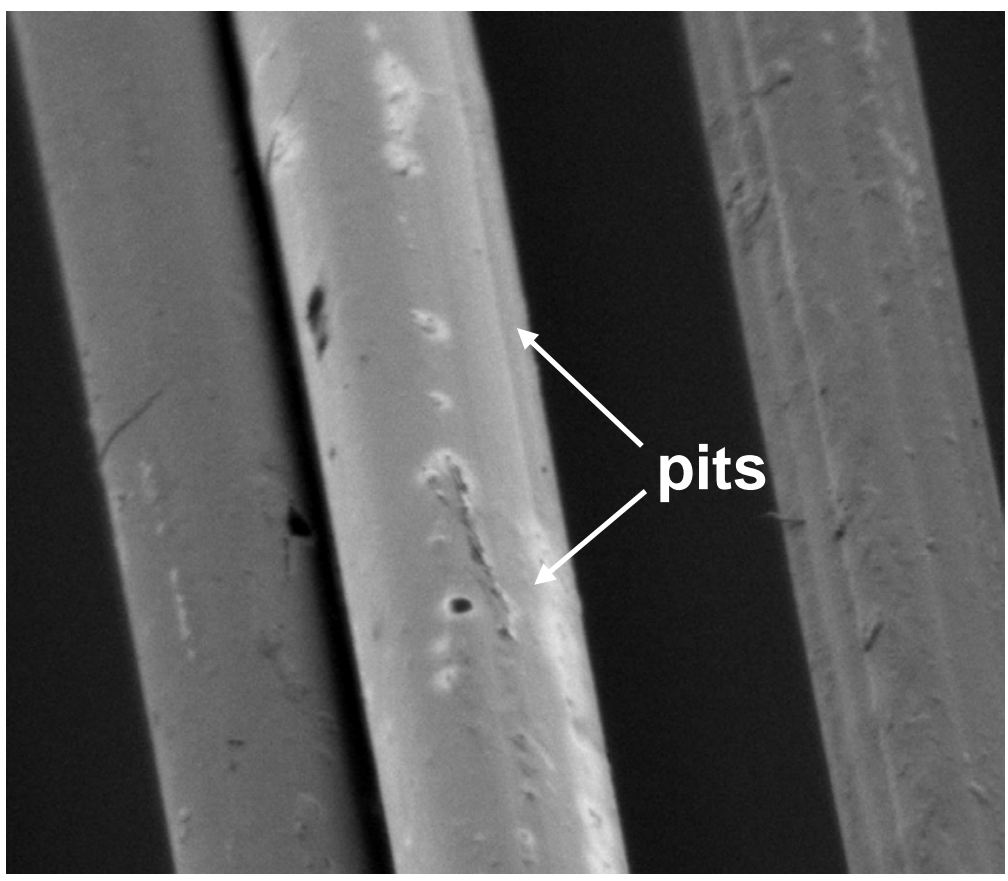

$500 \mathrm{~V}, 5 \mathrm{kx}, 50 \mu \mathrm{m}$ field width

(a)

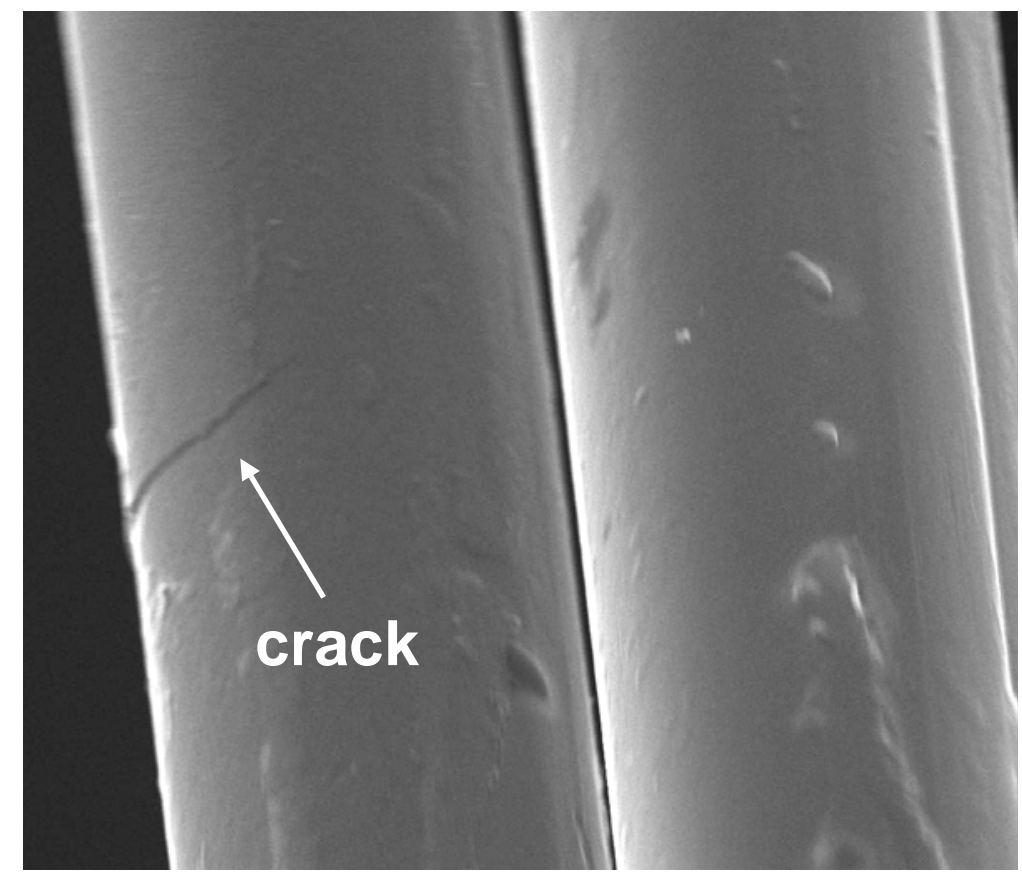

$25 \mathrm{kV}, 10 \mathrm{kx}, 25 \mu \mathrm{m}$ field width

(b)

Figure 5: SEM micrographs of fibers from officer's vest. 


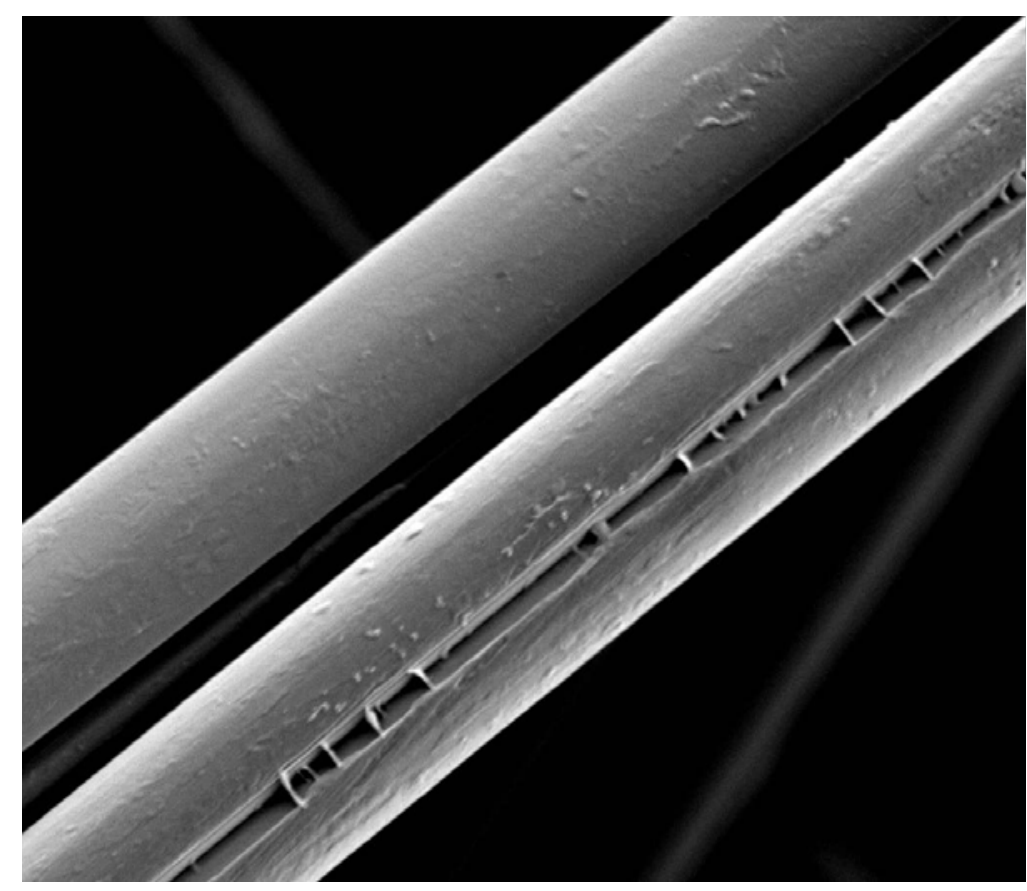

$25 \mathrm{kV}, 5 \mathrm{kx}, 50 \mu \mathrm{m}$ field width

(a)

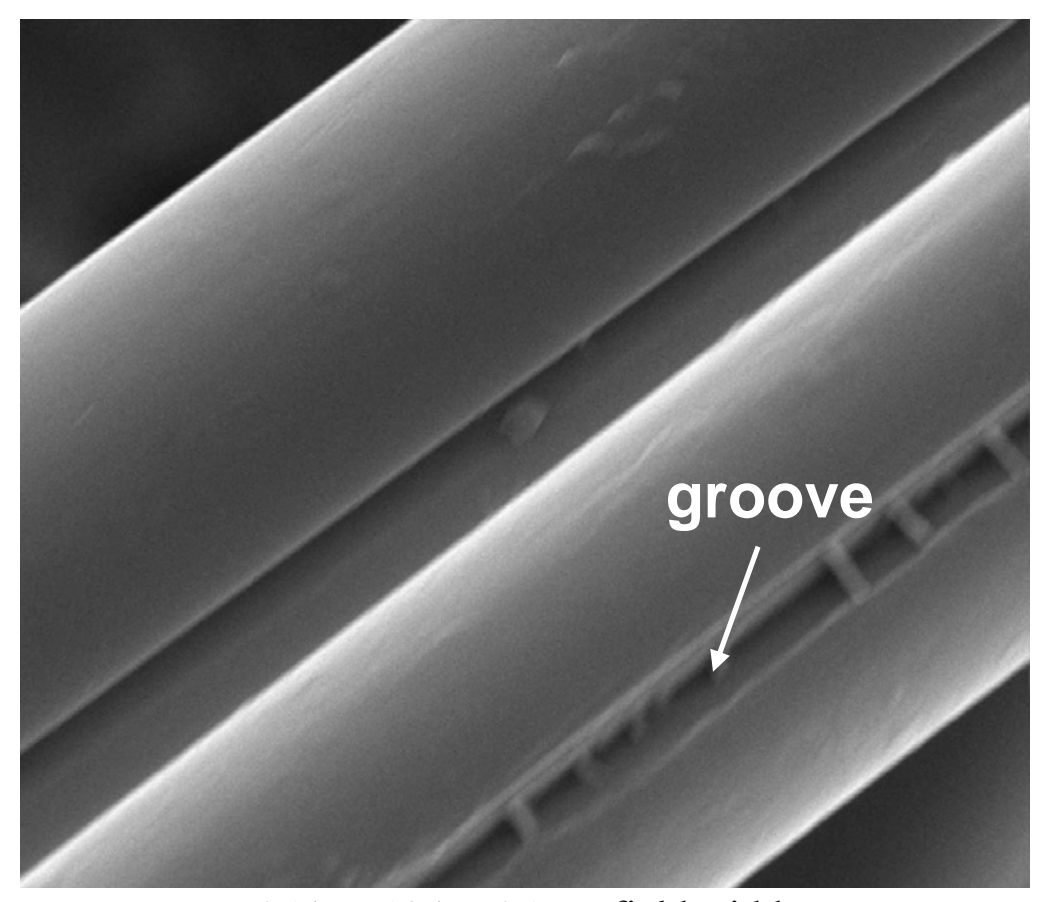

$25 \mathrm{kV}, 10 \mathrm{kx}, 25 \mu \mathrm{m}$ field width

(b)

Figure 6: SEM micrographs of fibers from new vest. 


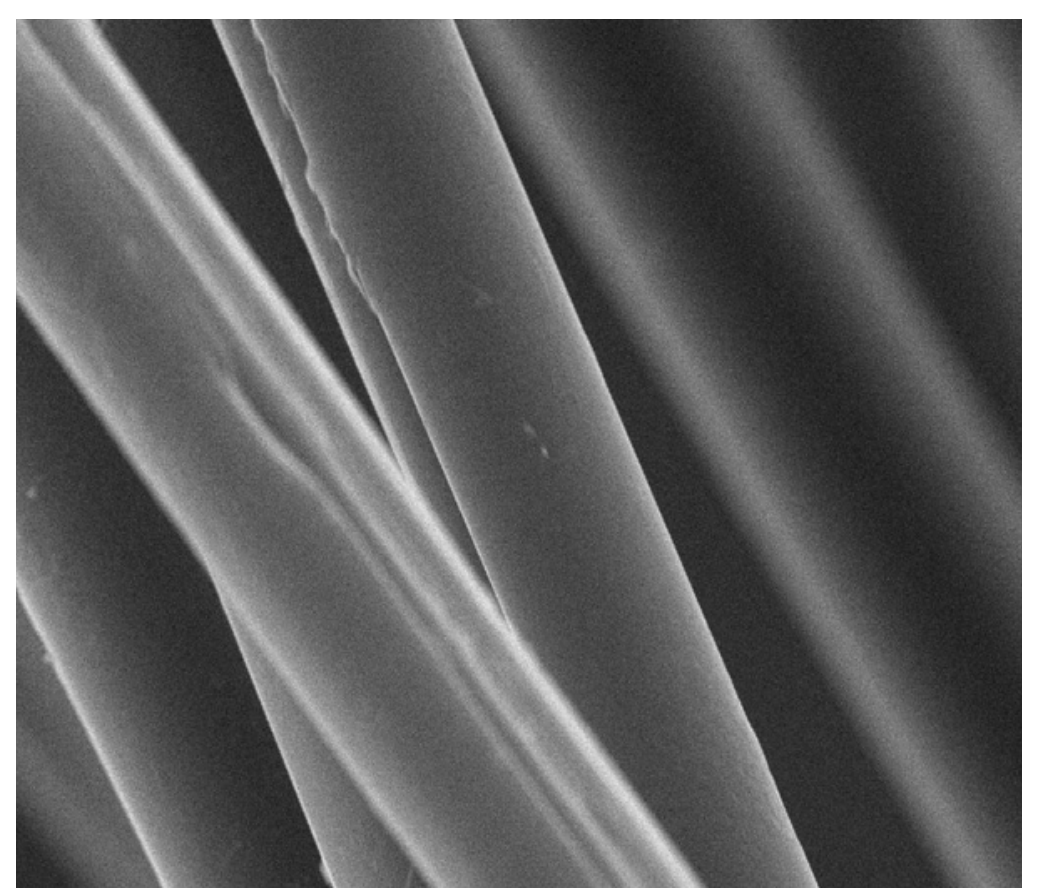

$25 \mathrm{kV}, 5 \mathrm{kx}, 50 \mu \mathrm{m}$ field width

Figure 7: SEM micrographs of fibers from archive vest. 


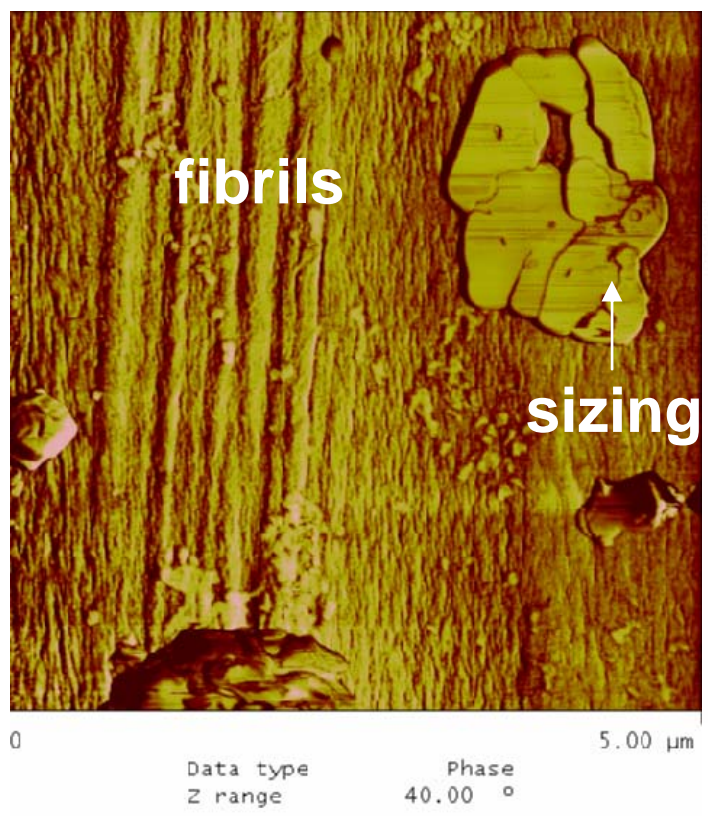

(a)

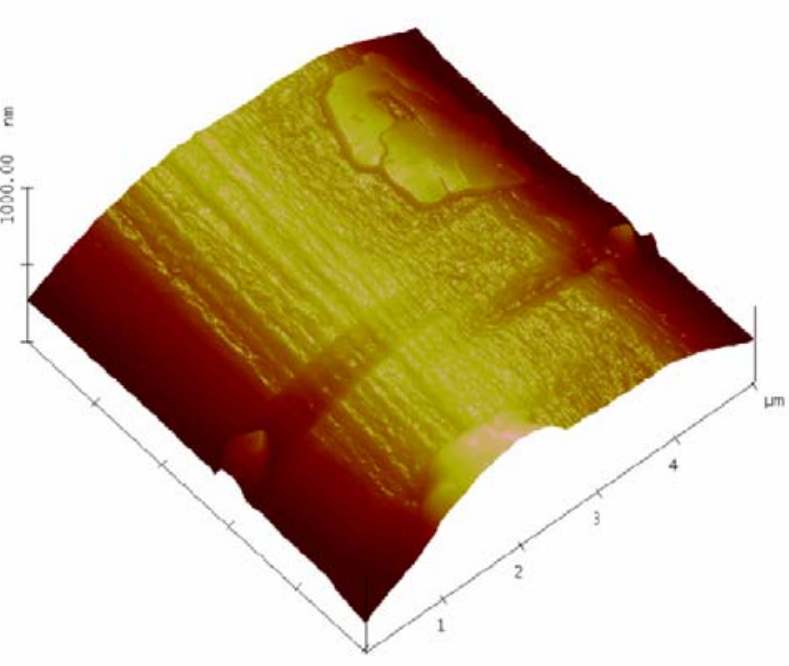

(b)

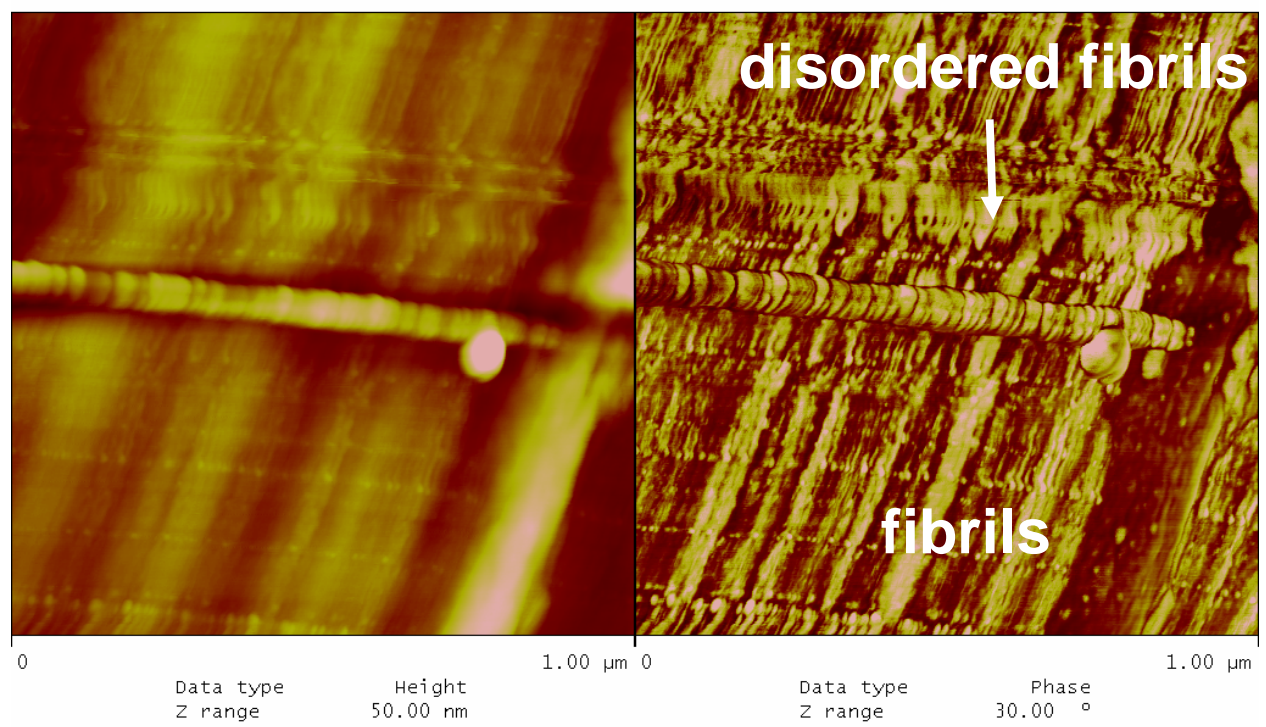

(c)

Figure 8: AFM micrographs of PBO fiber. (a) Phase image of fiber from officer's vest; (b) 3-D depiction of region shown in (a); (c) topographic and phase images of disordered region in fiber from officer's vest. 


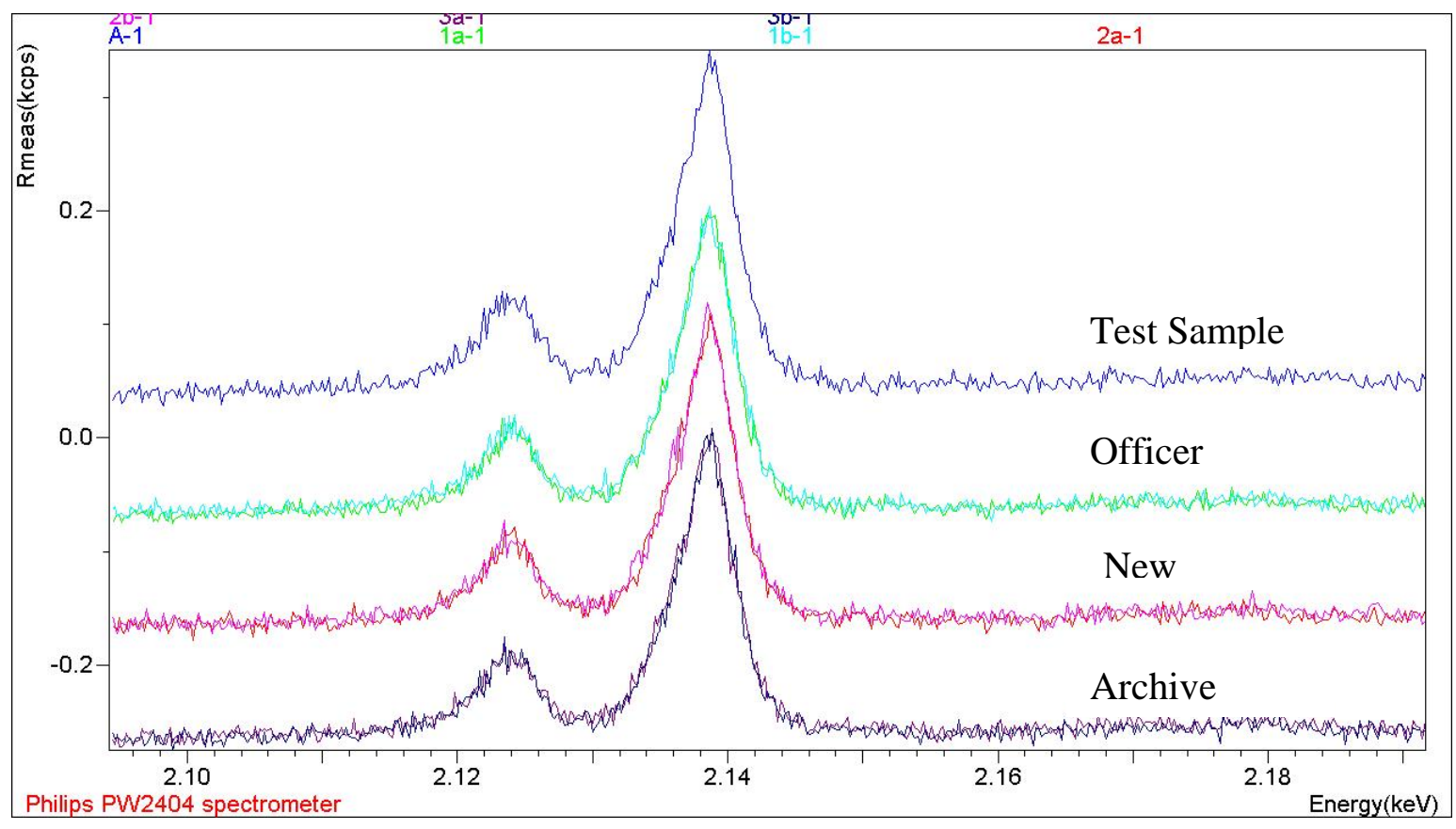

Figure 9: Phosphorus K-M series lines from vest yarns. Two scans from each vest are superimposed. 


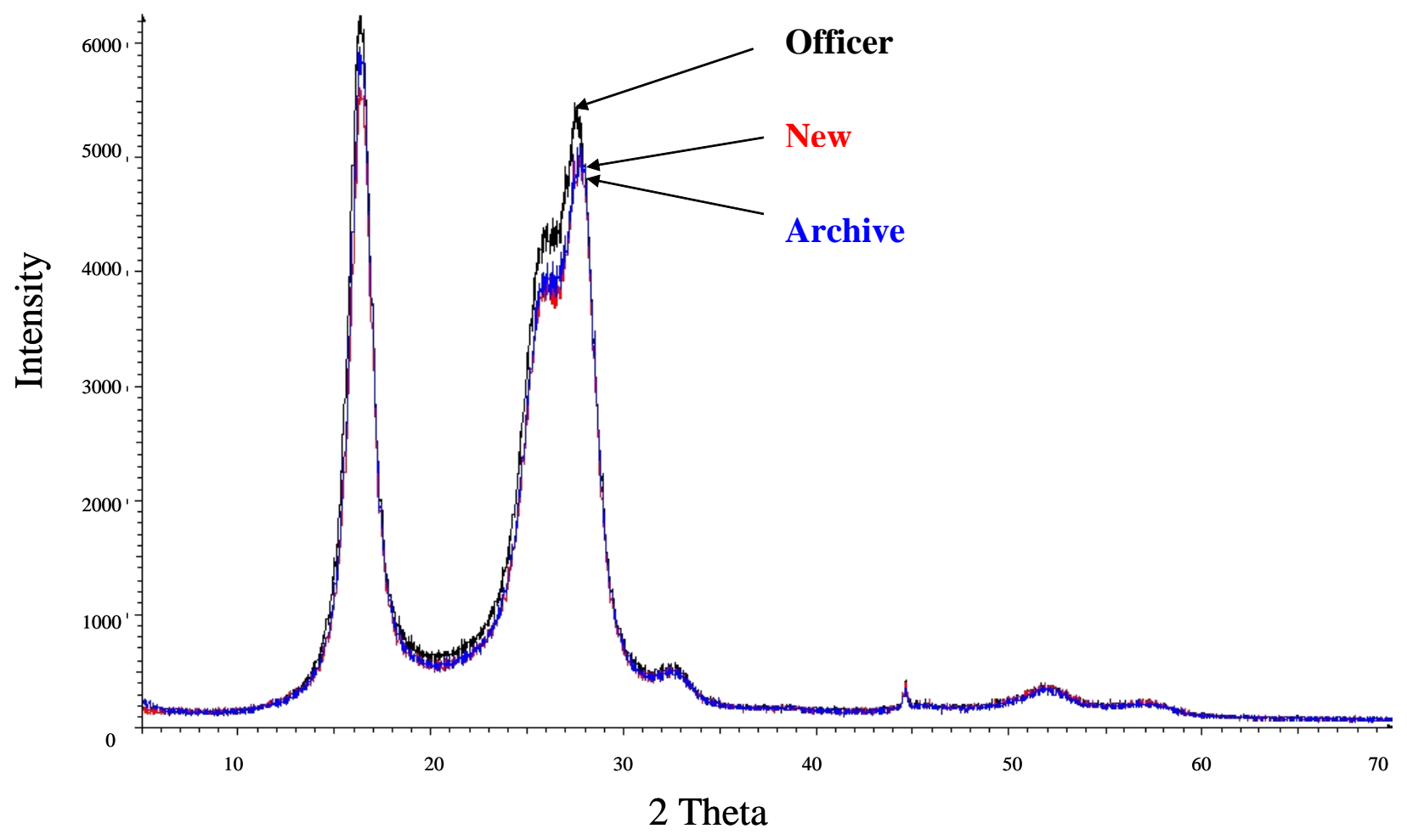

Figure 10: Comparison of equatorial x-ray diffractograms from vest yarns. 


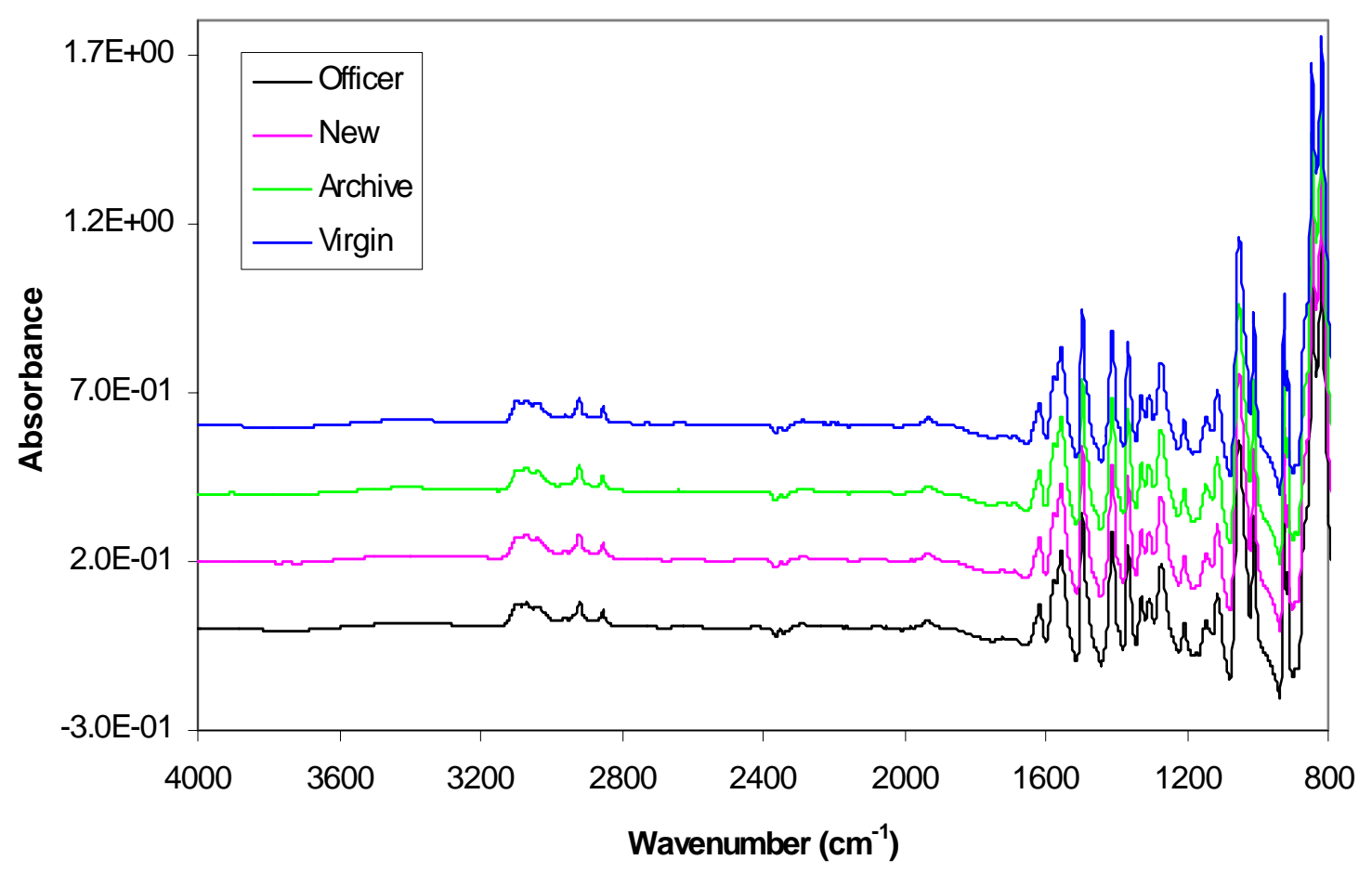

(a)

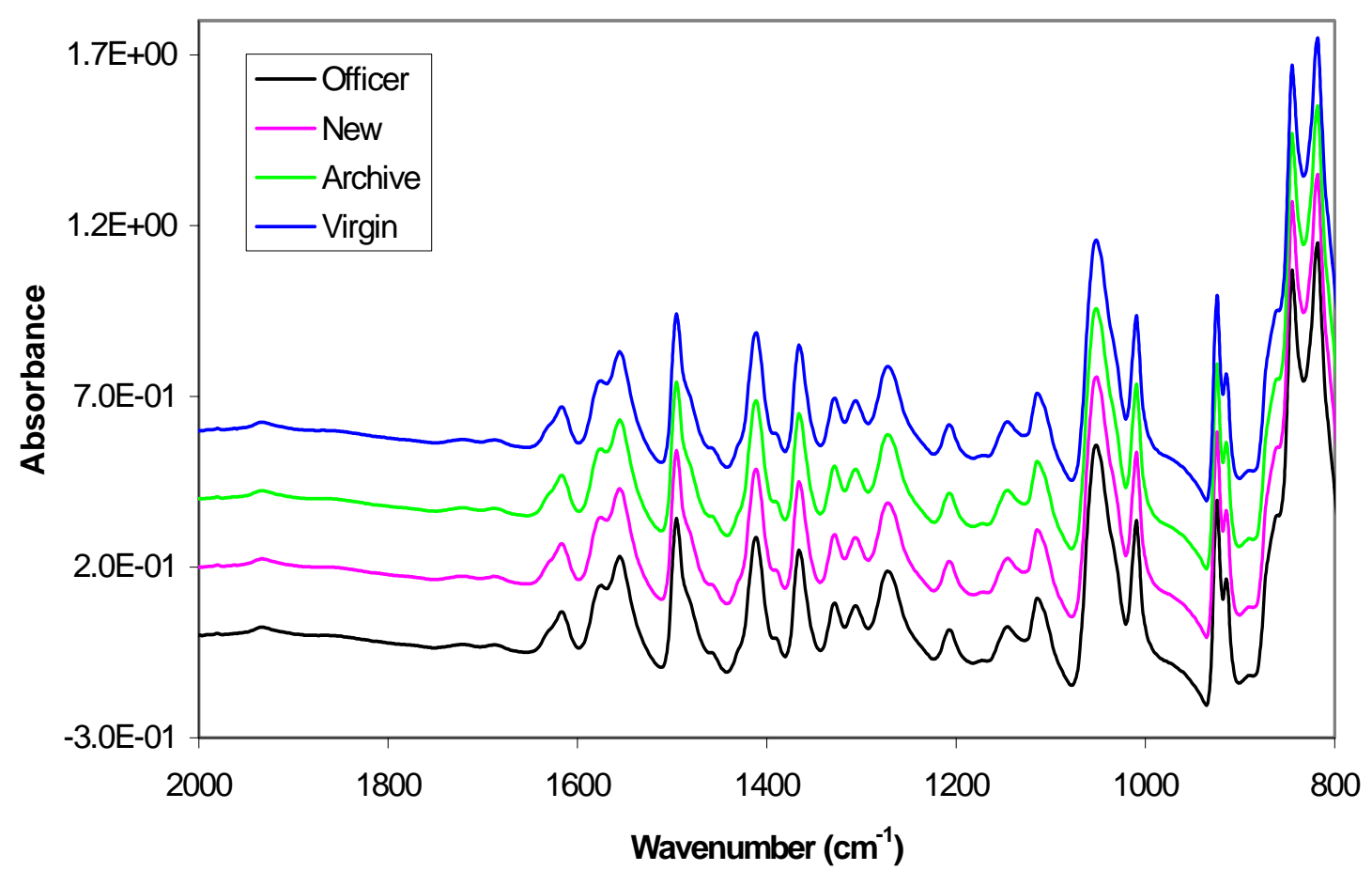

(b) 


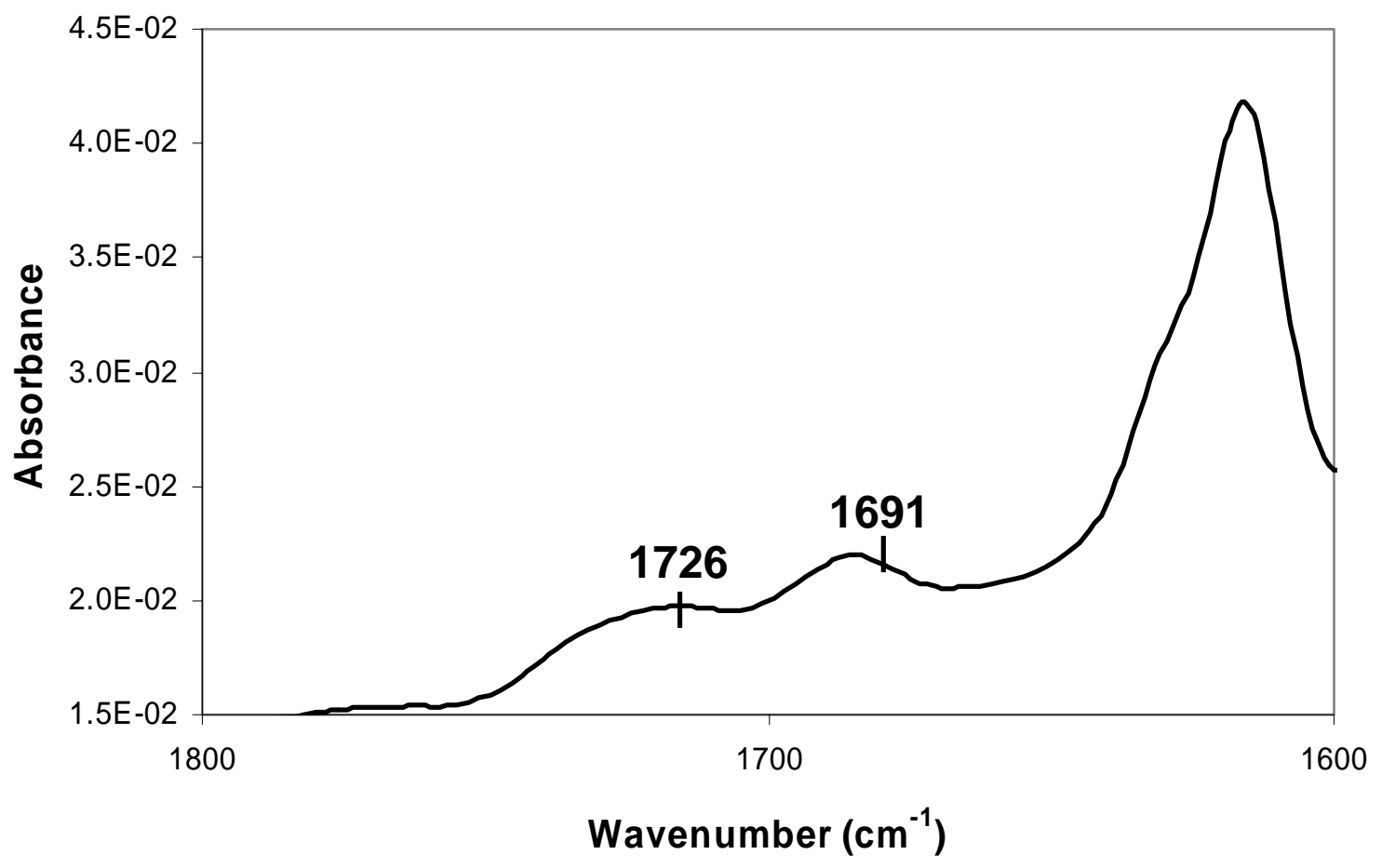

(c)

Figure 11: (a), (b) FTIR spectra of vest yarns, compared with virgin yarn. (c) Peaks at $1691 \mathrm{~cm}^{-1}$ and $1726 \mathrm{~cm}^{-1}$, observed in the infrared spectrum of all yarns analyzed. 


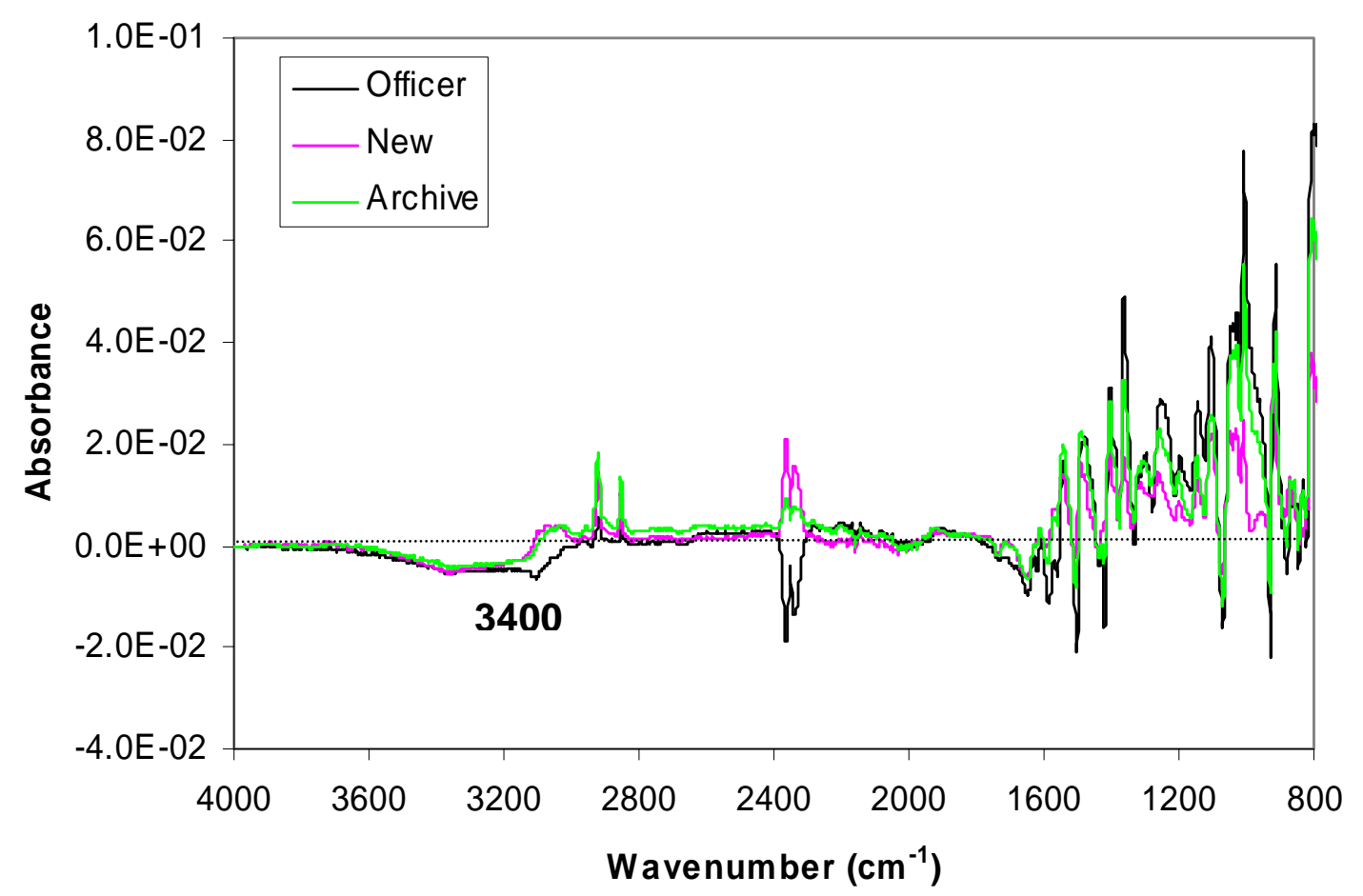

(a)

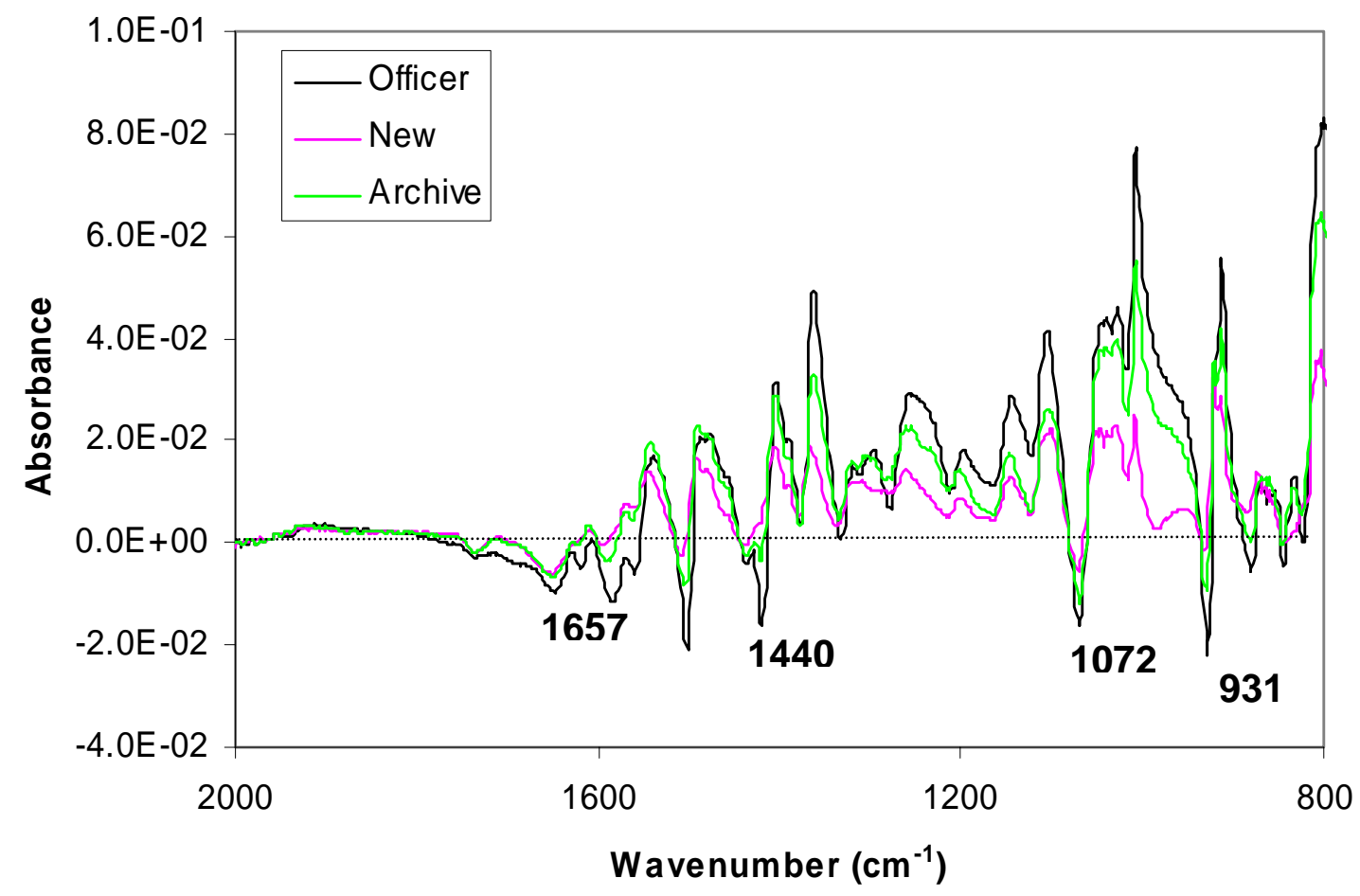

(b)

Figure 12: Difference spectra of vest yarns (referenced to spectrum of virgin yarn). Peaks matching those observed in the spectrum of N-(2-phenylhydroxybenzamide) are labeled. 


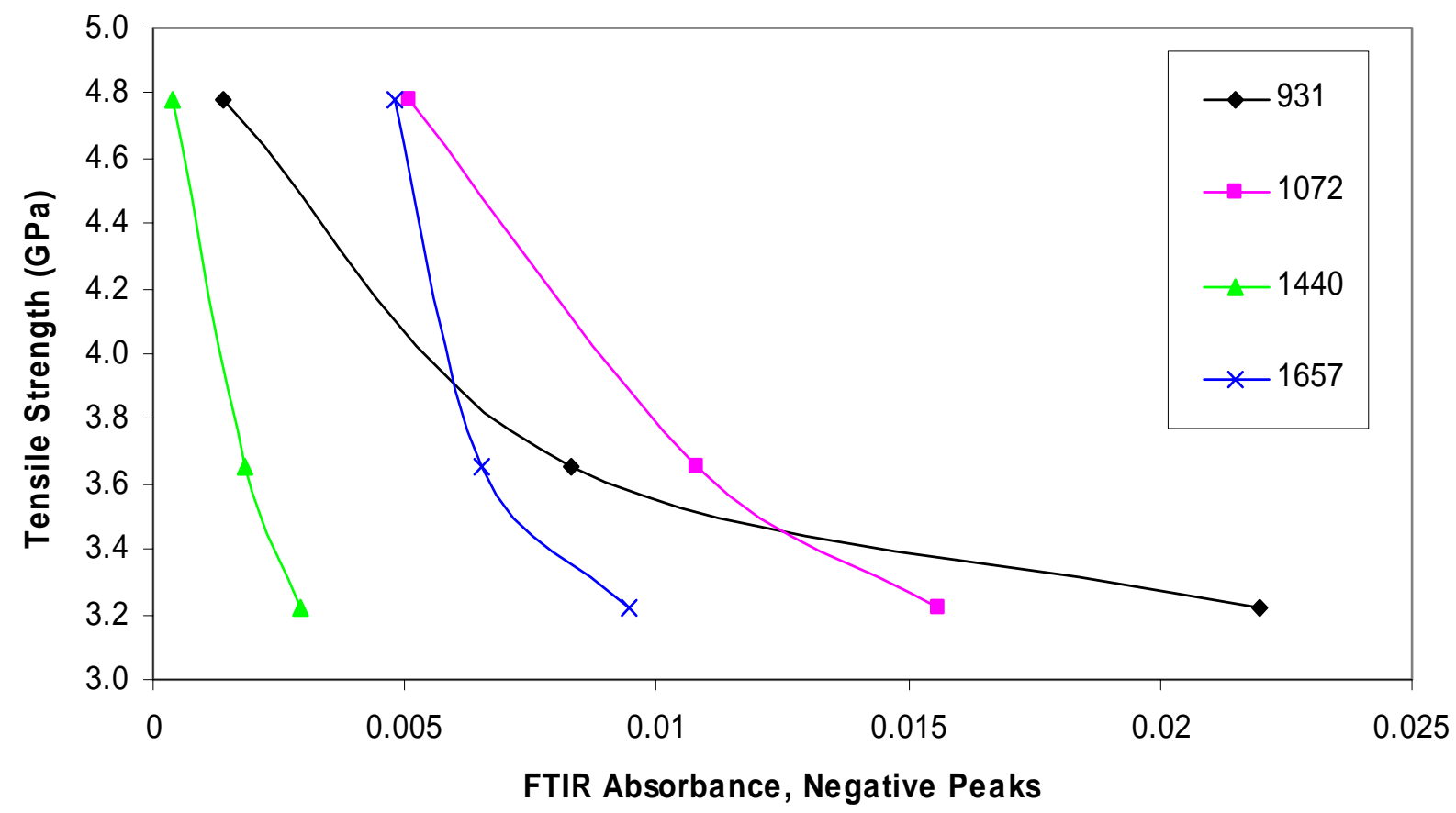

Figure 13: Vest yarn tensile strength plotted against the absorbance of negative subtraction peaks corresponding to benzamide species. 


\section{REFERENCES}

1. Department of Justice Bulletproof Vest Safety Initiative, 03-624 http://www.ojp.gov/pressreleases/DOJ03624.htm.

2. J.F. Wolfe, "Polybenzothiazoles and Oxazoles", in Encyclopedia of Polymer Science and Technology, 11, pp. 601-625.

3. X.-D. Hu, S.E. Jenkins, B.G. Min, M.B. Polk, and S. Kumar, Macromol. Mater. Eng., 288(11), 823842 (2003).

4. M.G. Northolt and J.J.M. Baltussen, J. Appl. Polym. Sci., 83, 508-538 (2002).

5. T. Kitagawa, H. Murase and K. Yabuki, J. Polym. Sci. B: Polymer Physics, 36, 39-48 (1998).

6. T. Kitagawa and K. Yabuki, J. Appl. Polym. Sci., 80, 1030-1036 (2001).

7. R. J. Young, R.J. Day, and M. Zakikhani, J. Mater. Sci., 25, 127 (1990).

8. http://www.toyobo.co.jp/e/seihin/kc/pbo/pdf/Attachment_1970KB.pdf

9. E. Orndoff, NASA Technical Memorandum 104814, Sept. 1995.

10. Y.-H. So, S.J. Martin, K. Owen, P.B. Smith, and C.L. Karas, J. Polym. Sci. A: Polymer Chemistry, 37, 2637-2643 (1999).

11. E.G. Breusova, R.T. Kuznetsova, T.N. Kopylova, and S.V. Nikolaev, High Energy Chemistry, 32(4), 247-250 (1998).

12. H. Ito and K. Ichimura, Macromol. Chem. Phys., 199, 2547-2551(1998).

13. P.H. Kasai and D. McLeod Jr., J. Am. Chem. Soc., 95, 4801 (1973).

14. B. Dickens in Service Life Prediction Methodology and Metrologies, J.W. Martin and D.R. Bauer, eds., (American Chemical Society, 2001).

15. C.C. Chau, J. Blackson, and J. Im, Polymer, 36 (13), 2511-1517 (1995).

16. Y. Cohen and E.L. Thomas, Macromolecules, 21, 433-435 (1988).

17. J.H. Greenwood and P.G. Rose, J. Mater. Sci., 9, 1809-1814 (1974).

18. C.C. Chau, M.H. Thomsen, and V.L. St. Jeor, J. Mater. Sci., 27, 5645-5652 (1992).

19. K. Tamargo-Martinez, S. Villar-Rodil, J.I. Paredes, A. Martinez-Alonso, J.M.D. Tascon, and M.A. Montes-Moran, Macromolecules, 36, 8662-8672 (2003).

20 . S.J. Krause, T.B. Haddock and D.L. Vezie, P.G. Lenhert, W.-F. Hwang, G.E. Price, T.E. Helminiak, J.F. O’Brien and W.W. Adams, Polymer, 29, 1354-1364 (1988).

21. R.J. Young, R.J. Day, M. Zakikhani, J. Mater. Sci., 25, 127-136 (1990).

22. T. Kuroki, Y. Tanaka, T. Kohudoh, K. Yabuki, J. Appl. Polym. Sci., 65 (5), 1031-1036 (1996). 
23. W.M. Riggs and M.J. Parker, "Surface Analysis by X-ray Photoelectron Spectroscopy", in Methods of Surface Analysis, A.W. Czanderna, ed., Elsevier, 1975.

24. NIST XPS database, http://srdata.nist.gov/xps.

25. H.H. Willard, L.L. Merrit, Jr., J.A. Dean, and F.A. Settle, Jr., Instrumental Methods of Analysis, 7th ed., Wadsworth, Inc., 1988.

26. X. Hu and A.J. Lesser, Proceedings of the American Chemical Society Meeting, Division of Polymeric Materials, Science and Engineering, 227, U562 (2004).

27. N. Sanjeeva Murthy and Franz Reidinger, “X-Ray Analysis”, in A Guide to Materials Characterization and Chemical Analysis, J.P. Sibilia, ed. (VCH Publishers, Inc., New York, 1996).

28. D.C. Martin and E.L. Thomas, Macromolecules, 24, 2450-2460 (1991).

29. R.J. Davies, M.A. Montes-Moran, C. Riekel and R.J. Young, J. Mater. Sci., 28, 2105-2115 (2003).

30. K. Tamargo-Martinez, S. Villar-Rodil, J.I. Paredes, A. Martinez-Alonso, and J.M.D. Tascon, Chem. Mater., 15, 4052-4059 (2003).

31. W.-Y. Yeh and R.J. Young, Polymer, 40, 857-870 (1999).

32. K. Tashiro, H. Hama, J.-I. Yoshino, Y. Abe, Tooru Kitagawa, and K. Yabuki, J. Polym Sci B: Polym. Phys., 39, 1296-1311 (2001).

33. J.-H. Chang, K. M. Park, S.-M. Lee, and J.B. Oh, J. Polym. Sci. B., 38, 2537-2545 (2000).

34. E.I. Yoo, A.J. Gavrin, R.J. Farris, and E.B. Coughlin, High Performance Polymers, 15, 519-535 (2003)

35. T. Kubota and R. Nakanishi, Polymer Letters, 2, 655-659 (1964).

36. G. Brana, E. Castellucci and M. Ginanneschi, Spectrochimica Acta, 23A, 751-758 (1967).

37. H. Ito and K. Ichimura, Macromol. Chem. Phys, 199, 2547-2551 (1998).

38. E.G. Breusova, R.T. Kuznetsova, T.N. Kopylova, and S.V. Nikolaev, High Energy Chemistry, 32 (4), 247-250 (1998).

39. P.F. Jackson, K.J. Morgan, and A.M. Turner, J. Chem Soc., Perkin Transactions II, 2 , 1582-1587 (1972).

40. Y. Termonia, P. Meakin, and P. Smith, Macromolecules, 18, 2246-2252 (1985).

41. M.-C. G. Jones and D.C. Martin, Macromolecules, 28, 6161-6174 (1995). 